\title{
Final Complementizers in Hybrid Languages
}

\author{
Josef Bayer \\ Friedrich-Schiller-Universität Jena
}

July 1996

revised June 1998 


\section{INTRODUCTION}

I call those languages hybrid which show a mix of final and initial heads. My goal in this article is to show that hybridity may not only be a surface phenomenon, but that certain forms of it may well be a phenomenon of the base of a given language. With respect to complementizers (which I call $C$ or in glosses $C O M P$ ), languages of this sort are being found in Northern and Central India, but surely elsewhere too. For instance, certain of Koopman's (1984) examples from Vata suggest that there is a final as well as an initial C: $n a$ appears initially in complement CPs in the context $\mathrm{V}_{-}$as in (1a), while $k a$ appears finally in complement CPs in the context _V as in (1b). ${ }^{1}$ Since the examples are drawn from various sources, no standardized transcription can be expected. For the representation of the Bengali examples, the following conventions are adopted: $R, T$ for retroflex consonants, $c, j$ for voiceless and voiced palatal stops, $\mathrm{S}$ for a palato-alveolar fricative, y for a high semi-vowel, $\mathrm{O}$ for a low vowel; after a consonant, $\mathrm{h}$ indicates aspiration; double consonants signal gemination.
a. màsIpànyÒ kà yi na Ò ká mÒ yamà healer FUT come NA he FUT you healthy-MA
"The healer will come to make you healthy"
b. màsIpànyÒ kà mÒ yamà ka yi
healer FUT you healthy-MA KA come
"The healer will come to make you healthy"

Koopman claims that only the latter is a complementizer. Generative research has always tried to deny a dual status according to which there would be final (FC) as well as initial complementizers (IC) in one and the same language. In practice, this means that only the element that falls into the expected typological picture is acknowledged while the other one that does not fit into this picture is declared to be some other kind of particle. I will explore a different direction here and suggest instead that complementizers may come from very different lexical and historical sources and may serve rather different purposes. Then the only reason to call a heterogeneous class "complementizers" would be that all of these elements are heads and that all of them have (among other functions) the function of indicating subordination. The category "complementizer" is - according to this view - a rather crude cover term that should not indicate total homogeneity. This has also been noticed in Bhatt and Yoon (1991) where a distinction is made between subordinating and mood-indicating complementizers. In this article where I will confine myself to the former, I will argue that within one and the same language subordinating particles which may legitimately be called "complementizers" can be heterogeneous according to their lexical nature, origin and word order. As I will show, tracing them back to one single underlying source would not only be a rather unilluminating exercise, it would also lead to a conflict with certain empirical finding and generalizations built on them.

While generative research in Principles and Parameters Theory (Chomsky, 1981 and subsequent work) has focused on parametrical choices according to which a language may have either initial or final complementizers (and preferably not both), it has been argued by Kayne (1994) that final complementizers (and ultimately all final heads) should not be seen as primitives but rather as the result of a PF-relevant operation by which the IP-complement 
of $\mathrm{C}$ has moved leftwards (Kayne, 1994: 53f). The reason for this is that, according to Kayne's theory, a linear order of the terminal elements in a phrase marker is dependent on the hierarchical c-command relation. Of course, classical c-command is independent of linear order, since in a pair [x YZ] Y c-commands $\mathrm{Z}$ and $\mathrm{Z}$ c-commands $\mathrm{Y}$. If c-command loses its autonomy in favor or a tight link with the anti-symmetric relation of precedence, it has to be narrowed down to asymmetric c-command: A asymmetrically c-commands B iff A precedes B. Since precedence is an asymmetric relation, c-command has to be asymmetric, too. The relation between linear and hierarchical order is captured by the Linear Correspondence Axiom (LCA). The LCA claims that the non-terminals in a given phrase marker are arranged by asymmetric c-command in such a way that the mapping from terminals to non-terminals always achieves an antisymmetric relation which is then in a position to determine a linear ordering. ${ }^{2}$ Thus, any difference in the linear ordering of terminals must correspond to a hierarchical difference. If a head $\mathrm{H}$ (asymmetrically) c-commands a phrase XP, then $\mathrm{H}$ must precede XP. ${ }^{3}$ It is a cornerstone of the theory that two constituents cannot achieve a linear ordering if they are in a relation of mutual c-command. Thus, a language which embraces both the structures in (2) would run into a linearization problem.

$$
\text { a. } \left.\left[\mathrm{C}^{\prime} \mathrm{C}[\mathrm{IP} \ldots]\right] \quad \text { b. } \quad\left[\mathrm{C}^{\prime}[\mathrm{IP} \ldots] \mathrm{C}\right]\right]
$$

The problem is clearly not that the terminals dominated by $\mathrm{C}$ and IP would not achieve any ordering due to the fact that the pairs of non-terminals cannot be in a relation of asymmetric c-command. The problem is rather the following: In (2a), there is an ordering according to which C precedes IP, but if ordering is once fixed in this way, precedence will be the ordering that holds in the language once and for all. Clearly, (2b) does not conform to this picture. We would say that C follows IP. ${ }^{4}$ We will discuss Kayne's solution in section 3.

The purpose of the present article is not to argue against this highly interesting and influential theory of phrase structure and word order per se, but rather to call the attention to some of its consequences which in my view lead to a number of undesirable results. In doing so, I will concentrate on the following aspects: Lexical choice of the complementizer, motivation for IP-movement, movement from SpecCP, and the positioning of CPs in general. The results of this investigation will suggest that the LCA in its present form is too strong a condition to be adopted as a principle of $\mathrm{UG}$, and that the word order variations involving $\mathrm{C}$ and IP are so far better explained by theories that admit parametric choices and blends. My data will mainly be drawn from South Asian languages, among which, due to my own research, Bengali data have a more prominent place.

\section{LEXICAL CHOICE}

FCs seem to be universally different from ICs. In the South Asian languages FCs are mainly degenerate verba dicendi; they are traditionally called quotatives, because they seem to set the preceding discourse in quotes. ${ }^{5}$ ICs, on the other hand, are in the South Asian languages usually degenerate operators or simply borrowed elements. Consider the following examples from purely head final languages as well as from hybrid languages: 
(3) Final complementizers in purely head-final languages (Dravidian)

\section{LANGUAGE FORM ORIGIN/FUNCTION}

\begin{tabular}{|c|c|c|}
\hline Telugu & ani & \\
\hline Tamil & endru & all of these derive from verba dicendi \\
\hline Kannada & anta & \\
\hline Malayalam & enne & \\
\hline
\end{tabular}

(4) 1. Final complementizers in hybrid languages (Southern and/or Eastern Indo-Aryan)
a. Bengali
bole
(past participle of bol- "say")
b. Oriya
boli
(past participle of bol- "say")
c. Assamese buli
(past participle of bol- "say"; used in
d. Marathi
asa optative clauses and elsewhere $)^{6}$
Marathi
Marathi
mhanun
("so", "thus")
te
(derived from "say")
e. Dakkhini-Hindi
bolke
(definite pronominal)
Dakkhini-Hindi
$-k i$
(bolkee = "having said")
(dubitative particle) $)^{7}$

Eastern Indo-Aryan)

2. Initial complementizers in hybrid languages (Southern and/or
a. Bengali
je
(relativization operator)
b. Oriya
je
(relativization operator)
c. Assamese
je
d. Marathi
(relativization operator)
e. Dakkhini-Hindi
$k i$
(originally "what")
$k i$
(originally "what")

There are two ways of dealing with this situation: The first one has already been mentioned. It means that one of the two options is denied, i.e., if for instance, Bengali bole is a complementizer, then je cannot likewise be a complementizer or vice versa. ${ }^{8}$ This was the argument of Bal (1990) with respect to Oriya, another South Asian language which is very close to Bengali. Bal is right in observing that $j e$ is actually a relativization operator. In Bayer (1996) it was argued, however, that this in itself is no proof against $j e$ 's status as a complementizer, because virtually any IC in the modern European languages is either identical with or historically derived from a Wh-operator. The following datum from Assamese to which Madhumita Barbora (p.c.) has drawn my attention suggests that $j e$ has been reanalyzed as a head:

$$
\begin{aligned}
& \text { moi ne -janu [ } \mathrm{kak}_{\mathrm{i}} \text { je bill-e juwal kali } \mathrm{t}_{\mathrm{i}} \text { dekhisil] } \\
& \text { I NEG-know who JE Bill-NOM yesterday seen-has } \\
& \text { "I don't know who Bill has seen yesterday" }
\end{aligned}
$$

If $j e$ is an operator, it would be strange for the Wh-operator kak to move to the left of it. If $j e$ is a complementizer, however, it is not totally unexpected to see an operator move into its specifier. ${ }^{9}$ I haven't been able to check these examples with a native speaker of Assamese. Thus, their status remains unclear at the moment. The same reviewer argues that related languages allow head-type material to the left of je but no Wh-phrase, and that this suggests 
that kak may be a left-adjoined head. But notice that, structure preservation provided, je would then likewise have to be a head. And this has precisely been my point. The reviewer is certainly right in asking why Wh-elements do not normally utilize a specifier position to the left of $j e$ or Hindi $k i$. Without a careful investigation of Assamese complementation any answer would be premature.

FCs, on the other hand, cannot easily be denied the status of a complementizer. Notice that all of the languages I am talking about are fairly consistently head-final languages. They have head-final VPs, PPs, APs; with the expectable exception of an IC-relative clause following the noun, most NPs are likewise head-final. ${ }^{10}$ I will return to the issue of head site and clause site in a different context. Thus, it would be conceptually awkward to deny final subordinators in these languages the status of a complementizer. From Marathi we have evidence that there may be more than one FC in a single language: According to Wali (1988), te can only be used in complements of factive verbs, whereas believe-type verbs require complements that are headed by asa or mha un.

a. [lili ghari geli \{te/*asa\}] Minila mahit ahe Lili home went TE/ASA Mini knows

"Mini knows that Lili went home"

b. [lili ghari geli $\{*$ te/asa $\}]$ Minila vatta

Lili home went TE/ASA Mini believes

"Mini believes that Lili went home"

Such variation is precisely what we see in the ICs of the modern Western languages where complementizers often vary with complement types. ${ }^{11}$ Its seems, thus, legitimate to take FCs as the parametrically unmarked cases in these languages, whereas IC may have been coined according to the model of other languages. ${ }^{12}$ It is suggestive that final morphemes with the meaning "thus", "so" or a semantically bleached verbum dicendi are an areal phenomenon on the Indian subcontinent that covers not only Sanskrit (witness the quotative iti to which I will briefly turn in the appendix) and many modern Indo-Aryan languages but also Dravidian. Languages that have according to standard descriptions exclusively ICs (in this case regularly the invariant particle $\mathrm{ki}$ ) such as northern Hindi and Kashmiri have been heavily influenced by Muslim culture, Persian and Arabic. In this situation it is not at all implausible that those languages which I call "hybrid" have developed heterogeneous complementizers, and as I will show heterogeneous forms of complementation. This is exactly the conclusion at which Singh (1977) arrives, who comments on the fact that Hindi has besides $k i$ also the final element ke liye (purposive "for") as shown in the following example:

mene Madhu se bethane ke liye kaha

I Madhu to sit for said

"I told Madhu to sit down"

According to Singh, $k i$ and ke liye can never change their position. The former is always initial, while the latter is always final. Singh's conclusion is nevertheless that $k i$ and $k e$ liye are both complementizers, a view that is also implicit in Mahajan (1990, ch.3). ${ }^{13}$ 


\section{MOTIVATION FOR IP-MOVEMENT?}

We have seen now that FCs and ICs may co-occur in one and the same language. The restriction to asymmetric c-command can, in principle, tolerate this state of affairs, but there is now another kind of reductionism involved: Since only one of the two structures in (2) can occur, if (asymmetric) c-command goes hand in hand with linear ordering, the other one must be derived. In Kayne's system, the only legitimate structure is (2a) i.e., a head-initial clause. ${ }^{14}$ Sabel's analysis is subject to the general problem of how to motivate extraposition (or, in this case, remnant extraposition). A more specific question would be why $k i$ should incorporate at the right edge of the matrix verb where in Hindi the inflectional morphemes appear, while the observed incorporation site is otherwise the left side of V. Thirdly, as we will see later, true FC-clauses (those in which $\mathrm{C}$ is spelled out as a FC) show full transparency for overt and for covert movement even in those cases where they are leftwards scrambled. In this case, the FC moves along with the scrambled clause. But if incorporation of the FC into the matrix verb is not required in this particular case, it seems less likely that this analysis should hold for the surface IC $k i$. Thus, (2b) must be derived from a clause headed by an IC. Antisymmetric syntax contains specific assumptions about specifiers. Specifiers have to be left-adjoined like left-adjoined adjuncts. This is connected to the assumption that adjoined-to phrases are segments in the technical sense of May (1985), and that segments fail to be the type of categories which play a role in asymmetric c-command. This allows subjects and other left-adjoined material to achieve a linear ordering of precedence in relation to the terminals dominated by the segment (the adjoined-to phrase). Movement to the left of $\mathrm{C}$ would then be either adjunction to $\mathrm{CP}$, i.e. $\left[_{\mathrm{CP}} \mathrm{XP}_{\mathrm{i}}\left[_{\mathrm{CP}} \mathrm{C}{ }_{\mathrm{IP}} \ldots \mathrm{t}_{\mathrm{i}}\right.\right.$ ...]]], or adjunction to a phrase headed by an invisible head (Y ) to the left of $\mathrm{CP}$, i.e. [YP $\mathrm{XP}_{\mathrm{i}}$ [YP $\left.\left.[\mathrm{Y}]\left[\mathrm{CP} C\left[\mathrm{IP} \ldots \mathrm{t}_{\mathrm{i}} \ldots\right]\right]\right]\right]$. Since the following considerations are neutral with respect to the technical prerequisites of asymmetric c-command, I will use the more familiar X-bar theoretic phrase structures.

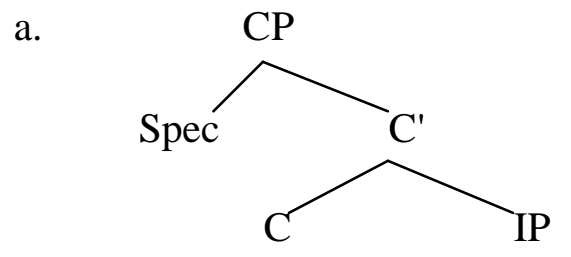

b.

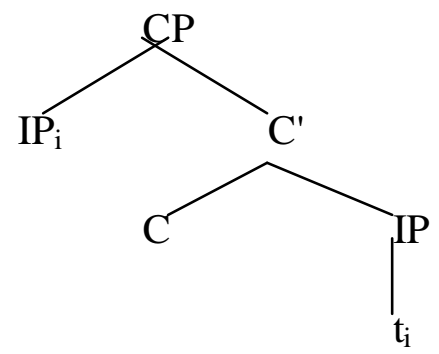

It is important to realize that according to Kayne's theory, which I will not introduce in more detail, $\mathrm{C}$ does not c-command IP in (8b), whereas it does in (2a) above. Underlyingly there are only ICs in this system. FCs are the result of IP-movement to SpecCP, as shown in the transition from $(8 \mathrm{a})$ to $(8 \mathrm{~b})$.

Kayne adduces three arguments in favor of this analysis:

(i) That-trace effects are only observed in IC- but never in FC-languages. If C is a blocking force that asymmetrically c-commands the subject trace, such a blocking effect would be absent in (8b).

(ii) IC-languages lack subject anaphors because again $\mathrm{C}$ asymmetrically ecommands the subject and acts as a blocking force against binding the subject anaphor (or, depending on the 
analysis, against movement of the anaphor). No such blocking effect will arise in FC languages.

(iii) FC-languages never show overt Wh-movement. If Wh-phrases use SpecCP as a landing site or as an escape hatch, the absence of Wh-movement is expected in such languages, because there SpecCP would always be filled by IP.

I will briefly comment on (i) and (ii), and defer a discussion of (iii) to section 4 . We will see that the observation underlying (iii) has to be modified. Concerning (i), there are clearly other ways of explaining the absence of that-trace violations. Many IC-languages do not show such an effect either; its appearance seems to be strongly connected to the rigidity of word order, here the unique placement of the subject. The FC-languages we are talking about here are extremely free in this respect. Thus, the absence of that-trace violations may not be so surprising, even if the FC-clause were an exact mirror image of an IC-clause. ${ }^{15}$ Concerning (ii), Kayne himself - p.142 - mentions a counterexample from Marathi: Despite the fact that Marathi has the Hindi-type IC ki, both types of long-distance anaphors pan and swat may be bound in subject position from outside as the following examples from Wali and Subbarao (1991) show:
a. lili samajte $_{\text {[ki }} \mathrm{apan}_{\mathrm{i}}$ libral ahot]
Lili believes that SELF liberal is
"Lili believes that she is liberal"
b. lili -ni $\mathrm{i}_{\mathrm{i}}$ sam - la ${ }_{\mathrm{j}}$ kalavla [ki swata $\mathrm{i}_{\mathrm{i}}$ kam karnar nahi] Lili-ERG Sam-to informed that SELF job do-FUT not
"Lili informed Sam that she herself won't do the job"

$K i$ does not seem to act as a blocking force against the binding of the reflexive. We may so far conclude that unless the argument in (iii) is extremely strong, Kayne's analysis is at best compatible with some of the data, but that no conclusive evidence has been shown in favor of it. Thus, it seems to be fair to say that the derivation seen in (8) is mainly motivated by the theory that disallows any version of symmetric ccommand. Let us therefore see to what extent the analysis in (8) could be justified.

How is movement motivated in general? According to the Minimalist Program (Chomsky, 1991; 1993; 1995), movement is a Last Resort operation that applies only in case the derivation of a sentence could not converge to a grammatical result otherwise. Overt movement is triggered, by and large, by a morphological requirement which is met by an operation of feature checking. Features are always either strong or weak. If a feature is strong, it must be checked before Spell-Out i.e., before phonetic realization. If a feature is weak, its checking (by movement) must be deferred to the post-Spell-Out part of the grammar (LF-component). The underlying assumption is that covert movement is more economical ("cheaper") than overt movement. Overt movement takes along more than is actually required for LF-convergence. This generalized Pied-Piping requirement is due to PFconvergence. In case a morphological requirement in terms of PF-convergence is lacking, movement will obligatorily be procrastinated. In principle, movement can be driven either by the item to be moved or by the target of movement. The first case falls under the principle of Greed, which Chomsky (1995: 201) characterizes as follows:

"Move- applies to an element only if morphological properties of itself are not otherwise satisfied. The 
operation cannot apply to to enable some element to satisfy its properties. Last Resort, then is always "selfserving": benefitting other elements is not allowed." ${ }^{16}$ For an approach of getting rid of the asymmetrical nature of the Greed principle see Lasnik's (1995) relaxation according to which movement may be driven by "enlightened self-interest", thus satisfying certain needs of the target.

Applied to the derivation shown in (8), Greed would require that there is a specific morphological property of IP that forces it to a higher position in which this property can be satisfied. The second possibility is that the target contains a feature in which case movement is a process of Attraction. There is a functional head H carrying a feature $\mathrm{F}$ that must be checked, and there is a (substantive) category that is able to check F. ${ }^{17}$ Applied to the derivation shown in (8), Attraction would require that $\mathrm{C}$ is endowed with a feature that can only be satisfied if IP is attracted by it, essentially terminating in the specifier of C. The theory of movement is generalized in the last chapter of Chomsky (1995) in such a way that feature checking is essentially a symmetrical process by which both the item to be moved and its target must be specified with the relevant feature, and that the best case of movement should consist of pure feature movement (Move-F). As before, movement of categories (Move- ) is only allowed in case PF-convergence cannot be met otherwise.

For the case of overt IP-movement at hand, the minimalist theory requires the presence of a strong feature in $\mathrm{C}$ that attracts IP, and that IP has a feature specification which is able to meet this requirement. Let us see now what kind of tangible evidence could lead us to the conclusion that the order IP-C is the result of IP-movement.

\subsection{Variability in the structure of IP?}

The first question to be asked is this: Does the IP in the languages under discussion vary in a way that would suggest a movement analysis in the spirit of the Greed principle. Such a case could be given in the syntax of the Dutch and German PP. ${ }^{18}$ The complement of a preposition may come in two varieties: As a full NP/DP or as the pronominal $d a$ or $w o$. In the case of the latter, the pronominal undergoes obligatory movement to the left of $\mathrm{P}$, whereby I leave it open whether this is movement to SpecPP or head-movement of the pronominal to P: ${ }^{19}$

$$
\begin{aligned}
& \text { a. mit dem Messer } \\
& \text { with the knife }
\end{aligned}
$$

$$
\begin{aligned}
& \text { b. da / wo +mit } \\
& \text { there where +with }
\end{aligned}
$$

Since the prepositions involved remain invariant, the reason for movement should be sought in the variability of the complement. While full DPs remain in situ, R-pronouns undergo movement. Assume that this is so because R-pronouns are intrinsically Case-less and derive Case properties by overt D-feature checking.

Can a similar motivation be constructed for IP-movement in hybrid languages? The fact that the FC ke liye in Hindi is confined to non-finite IP, while the IC $k i$ is confined to finite IP seems to invite an analogous analysis. In that case, the non-finite IP would have to undergo leftward movement, and the complementizer would be the functional category licensing the IP. ${ }^{20}$ See also Mahajan (1990: ch.3) where it is observed that in Hindi infinitivals including those headed by ke liye can be extraposed but then show a flavor of markedness. More globally, this generalization cannot be retained, however. Consider the following Bengali data for which Singh (1980) and Bayer (1996) have claimed that bole and je are instances of 
FC and IC respectively:

(11) a. chele-Ta [[or baba aS -be] bole ] Sune-che

boy-CF his father come-FUT3 COMP hear-PTS3

"The boy has heard that his father will come"

b. chele-Ta Sune-che [je [or baba aS -be]]

boy-CF hear-PTS3 COMP his father come-FUT3

IP remains identical in the two cases. This is not to say that there are no differences between je-clauses and bole-clauses. As Singh (1980) has pointed out, bole-clauses can also be used as reason adverbials and in a number of not well-understood functions, while $j e$-clauses cannot. Furthermore, as Probal Dasgupta (p.c.) has pointed out, de-focused material can be moved to the right of the finite verb of a je-clause, while this is never possible in a bole-clause. In the latter, bole must not be separated from the verbal complex of the IP headed by bole. A natural reason for this seems to be that bole, actually being a verb, must be contiguously linked to the verbal complex at the right edge of IP. ${ }^{21}$ While the complements of bole and je are certainly subject to different restrictions, as can be expected, the existence of the pair in (11) makes it hard to argue in favor of IP-movement in terms of the nature of the IP involved. In particular, it would be unclear along which dimension of feature struc ture the IPs involved could vary. To return to the comparison with West-Germanic PPs, it looks as if both the orders P-Rpronoun and R-pronoun-P were simultaneously possible.

\subsection{Positional variability of C?}

Consider now the other possibility according to which the trigger for a derivation as in (8) rests in $\mathrm{C}$ rather than in IP. In that case, we would expect cross-linguistic variation according to which the strength of the relevant feature in $\mathrm{C}$ differs from one language to the other: If $\mathrm{C}$ has a weak feature, IP will not raise, or at least not overtly, the result will be an IC-clause; if $\mathrm{C}$ has a strong feature, IP will raise overtly, and the result will be an FC-clause. ${ }^{22}$

However, the variations shown in (12) are not attested anywhere in Bengali or its dialects, and seem to be seriously ungrammatical: ${ }^{23}$

(12) a. *chele-Ta Sune-che [[or baba aS-be] je]

b. * $\quad *$ chele-Ta [ bole [or baba aS-be]] Sune-che

As far as I know, such variation does not arise in closely related hybrid languages either. ${ }^{24}$

An exception could be Dakkhini-Hindi, where we find both initial and final $k i$ (see note 7). Davison (1993) quotes the following example from Arora (1985):

(13) kis -ki [raam kab aataa $\{\mathrm{ki} / * \varnothing\}$ maalum? who-DAT Ram when comes DUB / Ø knowledge

"Who knows when Ram will come?"

As has already been pointed out in note 7 , however, the $k i$ involved here is a clitic-like element with the semantic feature + wh (or $+\mathrm{dub}$ ), a property that the IC $k i$ lacks entirely.

Even if there was proof that the IC $k i$ stems from the same lexical source (having the meaning 
"what") as Klaiman (1977) suggests, FC and IC must, for the present speakers, be different lexical items with distinct feature structures and different meanings. Thus, the postulation of a derivational link between initial $k i$ and final $-k i$ appears to be unmotivated.

It seems that positional variability of $\mathrm{C}$, according to which one and the same lexical element would once be an IC and another time a FC, is never observed in the synchrony or in the diachrony of the languages at hand. ${ }^{25}$ sè as well as $-s$ seem to be the same morpheme, namely a quotative verb of saying. Saxena says that the full form (sè) may be deleted, and that -na seems to occur only in direct quote constructions where sè is present. The IP-movement theory would have to say that IP raises to the specifier of $-s$, but refrains from raising to the specifier of the non-affixal form sè. Since there are now two heads with roughly the same function, and since there is $n a$ as one further functional category, it is not easy to come up with a straightforward description of this example in any current theory. Such variability could, however, be expected, if the restrictive theory that enforces a derivational analysis of FC-sentences should not remain a purely theoretical issue.

\subsection{Are FCs affixal?}

An argument in favor of IP-movement to SpecCP could be that $\mathrm{C}$ is an affix, more specifically an enclitic element. In this case, one could argue that IP moves to the pre-C position in order to enable $\mathrm{C}$ to undergo cliticization. IP-movement would then be triggered by what Lasnik (1981) has proposed as a filter against stranded affixes. In Minimalist terms, the trigger would be either a strong feature in $\mathrm{C}$ that attracts IP, or movement would have to be guided by "enlightened self-interest" (see note 16), a movement which would prevent the structure from "crashing" at the PF-interface. I cannot determine by which independent reasoning one would call the Dravidian quotatives in (3) "affixal", but there does not seem to be an obvious (for instance, phonological) reason for attributing this quality to the Bengali FC bole that appears in (11a). Bole in this function does not differ phonologically from its homophonous counterpart which is a participle of the verb "to say". ${ }^{26}$ Furthermore and perhaps more importantly, as pointed out in Dasgupta $(1980 ; 1983 ; 1984 ; 1987)$, Bengali has a use of $j e$ which suggests that $j e$ (rather than bole) may function as a clitic-like element: ${ }^{27}$

$$
\begin{aligned}
& \text { a. chele-Ta [or baba je aS -be] Sone-ni } \\
& \text { boy-CF his father JE come-FUT3 hear-NEG/PTS } \\
& \text { "The boy hasn't heard that his father will come" } \\
& \text { b. [or baba je aS-be] chele-Ta Sone-ni }
\end{aligned}
$$

If in (14) je is an enclitic element that attaches to $b a b a$ like an affix, and if it is unselective to its host category as seems to be the case in Bengali, we may wonder why it cannot attach to the finite verb as in (12a). ${ }^{28}$ We will later turn to the question whether an altruistic operation like that should cause movement of the entire IP. At this moment, it is enough to see that Bengali does not provide any PF-motivation for such movement: If one of the two functional elements under discussion has affixal status at all, it is at best je but not bole. Thus, from a PF-perspective of attraction, the fact that bole rather than $j e$ is the FC found in this language is unexpected.

Another piece of evidence against the stray-affix explanation of IP-movement is provided by Hindi, if we follow Singh (1977) and Mahajan (1990) in taking ke liye as in (7) to be a 
complementizer. Comparing the IC $k i$ with the FC ke liye, it should be the former and not the latter which acts as a stray affix that needs to be supported by IP. Morphologically ke liye is clearly less clitic- or affix-like than $k i$; so why should IP move into the specifier of ke liye, while it must not move into the specifier of $k i ?^{29}$

Provided that the mere phonological weight of the FC cannot serve as an explanation for IPraising, the trigger for movement would have to rest in the functional syntactic system. Here it is interesting to notice that Bengali postpositions are generally derived from verbal participles, e.g. diye ("by means of") from de- ("give"), theke ("from") from thak- ("stay"). If we include bole in this scenario as suggested by Klaiman (1977: 304), we could say that the FC is actually a postposition, and so could be Hindi ke liye. While this reasoning may be on the right track, it is, of course, neutral to the question of IP-raising. If all Bengali and Hindi PPs are head final, so would be clauses headed by bole or ke liye. Whether the head final order is derived from a head initial order is a different issue, and as far as we could determine there is no independent reason to assume such a movement process for the languages under discussion. We will return to this issue in section 5.

\subsection{Why IP-movement?}

We have seen so far that in hybrid languages FCs are always lexically distinct from IC. If FCs are ICs in disguise by the fact that IP is moved into their specifier, we should now ask a question that gains importance with respect to Minimalist assumptions: Why would ATTRACT/MOVE affect the entire IP? In other words, why should the strong feature on C have to be checked by Pied-Piping the entire IP to SpecCP? Notice that movement of IP should raise our suspicion. To my knowledge, it has not been convincingly attested anywhere else. Extraction of IP out of CP with a stranded C as in (15a) is completely impossible. Topicalization of an "unsupported", i.e. COMP-less, complement as in (15b) amounts to what Ross (1973) has dubbed Slifting (S-lifting). Slifting is subject to very specific constraints, as the ungrammaticality of $(15 \mathrm{~b})$ indicates.

(15) a. $\quad *\left[[\text { Bill is intelligent }]_{i}\left[\right.\right.$ Mary couldn't know that $\left.\left.\mathrm{t}_{\mathrm{i}}\right]\right]$

b. $\quad *\left[[\text { Bill is intelligent }]_{\mathrm{i}}\right.$ [everybody thinks $\left.\left.\mathrm{t}_{\mathrm{i}}\right]\right]$

c. $\quad *\left[[\text { Him leave the house }]_{i}\left[\right.\right.$ we could not see $\left.\left.t_{i}\right]\right]$

Despite occasional claims to the contrary, topicalization of bare infinitives as in (15c) seems to be equally bad. ${ }^{30}$ topicalizations are possible in certain varieties of Yiddish. Finite IPs as well as bare infinitives seem to depend very much on a strictly local functional licenser. Thus, IP-raising would, in all likelihood, have to be restricted such that it can target only the specifier of its own C. But even if we assume a derivation of FCs along these lines, it is unclear why in each case the entire IP would move. In the Minimalist framework, PiedPiping is a Last Resort operation that is supposed to carry along the absolutely minimal lexical material that would cause the structure to converge at PF. Given the general mobility of objects as well as subjects in head-final languages, it is hard to see why in each case the entire IP would move instead of - say - some of its substructure that carries the purported feature. In (11a), this feature would, for instance, rest in the finite verb $a S$-be. Thus, given the fact that various languages of the world show raising of the finite verb to $C$ (the verb-second phenomenon), and given that Bengali as well as all the other languages under discussion allow scrambling, some variation would be expected according to which it is not the entire IP 
that undergoes movement but rather the substructure whose features match with the purported feature of $\mathrm{C}$. To my knowledge, such variation is not attested in any of the languages under consideration. In Bengali, movement of the finite verb toward bole in the sense of V-to-I-to-C movement yields an ill-formed sentence:

$$
\text { *chele-Ta }\left[\left[\left\{\left[a S_{j}-b e\right]_{i} \text { bole }\right\} \text { [or baba [I' }\left[\mathrm{vP}_{\mathrm{j}}\right] \mathrm{II}_{\mathrm{i}} \mathrm{t}_{\mathrm{i}}\right]\right] \text { Sune-che }
$$

Koopman (1995) develops a theory of phrase structure in which every projection must be lexically activated. Activation of a projection XP is either achieved by insertion of an overt specifier (SpecXP) or by insertion of an overt head X. ${ }^{31}$ In her theory, a Dutch or English yes/no question would be formed in either of two ways: By lexicalization of the Q-head (more conventionally a C-head) as in (17a) or by lexicalization of SpecQP (SpecCP) as in (17b). The latter is achieved by IP-raising.

(17) a. $\quad\left[\mathrm{QP} \varnothing\left[\mathrm{Q}^{\prime}[\mathrm{Vfin} \text { did }]_{\mathrm{i}}\left[\mathrm{IP}\right.\right.\right.$ John $\mathrm{t}_{\mathrm{i}}$ leave $\left.\left.]\right]\right]$ ?

b. [QP [IP John left $]_{i}\left[Q^{\prime}[Q \varnothing]\left[\mathrm{Q}_{\mathrm{P}} \mathrm{t}_{\mathrm{i}}\right]\right]$ ?

(17b) is then the representation of a question with a rising intonational contour. The connection between Koopman's considerations and the Bengali pseudo-V2 example in (16) is obvious: If something is attracted by $\mathrm{C}$, the minimal structure suitable for feature checking will move, and this minimal structure is, of course, $\mathrm{I}^{\mathbf{0}}$ rather than I' or IP. But given the mobility of $\mathrm{I}^{\mathrm{o}}$ in V2-languages and residual V2-languages, how could IP ever be attracted? Ian Roberts (p.c.) suggests that V-final languages might lack V-to-I movement in general, in which case $\mathrm{V}$ must come fully inflected from the lexicon. If $\mathrm{C}$ wants to attract a lexicalized $\mathrm{I}$, we may derive a reason for the entire VP/IP to move, i.e. for Pied-Piping of IP. Assume that OV-languages indeed lack V-to-I, or that these languages do not build up an I-projection in the first place as Haider (1993) has argued on the basis of German V-final sentences. In this case, the bare infinitival form of the verb would be drawn from the lexicon. If the functional element $z u$ ("to") is a complementizer for infinitival clauses, as Wilder (1988) has argued, the VP would be attracted to the specifier of $z u$. But this yields the wrong word order *[[... V] $z u]$ instead of the attested [[...] $z u \mathrm{~V}]$. If $z u$ heads a head-final IP instead, V-to-I straightforwardly leads to the attested structure. With respect to Bengali, certain facts are under current assumptions not easily compatible with a lexical generation of the inflected verb. As Bayer and Lahiri (1990) have shown, the past participial form, which is a phonological word and enters further affixation, may undergo reduplication, and it may also be followed by the emphatic clitic-o ("also", "too"). Thus, the verbal form mer-e-ch-i-l-am (beat-PPT-ASPECTLINK-PTS-1) can be split up in the following ways: mere-Tere-chilam ("I have beaten etc."), mere-o-chilam ("I have also BEATEN"). I take this as evidence for a split-INFL analysis, attachment of $-o$ to $\mathrm{VP}$, and rightward head movement. Thus, if $\mathrm{FC}$ is an attractor of $\mathrm{F}$ features, Fmovement to FC would be expected rather than IP-movement to SpecFC. One should notice in this connection the interesting fact that the languages under consideration must have a high chance of developing the V2 property. As a matter of fact, Kashmiri which is closely related to Hindi, is a V2 language. As the data in Bhatt (1993) and Wali and Koul (1997) show, it is clearly not an IP-moving language. It should be noticed that Kashmiri is also V2 in embedded clauses (which are headed by the IC $k i$ or $z i$ ). FCs seem to be missing entirely. I take this to be an indirect demonstration that FCs in closely related languages should not be analyzed as attractors of IP. 
Koopman suggests that her analysis would also account for examples in which IP seems to be moved to the left of the matrix clause in the sense of Ross's (1973) Slifting rule. Consider the data in (18) of which Koopman discusses (18b).

(18) a. Bill is intelligent, \{I guess / she thought / we believe $\}$

b. Who came do you think?

According to her theory, (18b) has the structure in (19)

$$
\left[\text { CP }[\text { IP who came }]_{\mathrm{i}}\left[{ }_{\mathrm{C}} \varnothing\left[\mathrm{IP} \mathrm{t}_{\mathrm{i}}\right]\right]_{\mathrm{k}}\left[\left[\emptyset_{\mathrm{WH}}[\mathrm{do}]_{\mathrm{j}}\left[\mathrm{IP} \text { you } \mathrm{t}_{\mathrm{j}} \text { think }\left[\mathrm{CP} \mathrm{t}_{\mathrm{k}}\right]\right]\right]\right] ?\right.
$$

The matrix clause is you do think ... Raising of do lexicalizes a $+\mathrm{Q} /+$ wh projection. The $\mathrm{CP}-$ complement of think raises to the left. Since its C-head is empty, its IP-complement (which must now carry a +wh feature although who stays in situ) undergoes raising, essentially lexicalizing the projection of C. (18a) would similarly involve IP-movement to the specifier of an empty C-head. I see two problems with this proposal: First, if in (18b) CP is raised as indicated in (19), and if traces are still what they used to be in syntactic theory, then reconstruction would be expected. However, since a wh-clause cannot be selected by think, the sentence should be deviant. ${ }^{32}$ Koopman's account would have to provide a reason why reconstruction is blocked in this case. Secondly, cases like (18a) are much more restricted than the sentence types that correspond to their alleged underlying structure. Consider the pairs in (20) through (22):

(20) a. Every teacher in this school thinks Bill is intelligent

b. ??Bill is intelligent, every teacher in this school thinks

(21) a. $\quad\{$ I guess / she thought / we believe $\}$ that Bill is intelligent

b. $\quad *$ that Bill is intelligent $\{$ I guess / she thought / we believe $\}$

(22) a. She shouted *(:) "Leave me alone!"

b. $\quad$ "Leave me alone!", she shouted

The contrast in (20) shows that the "size" of the matrix clause plays no role in (20a), while it does in (20b). The awkwardness of (20b) disappears, if as is inserted: Bill is intelligent, as every teacher in this school thinks. But the resulting structure requires that the as-clause is an adjunct to the main clause Bill is intelligent, and thus irrelevant for Koopman's argument. (21b) shows that a CP with a lexicalized C-head cannot be topicalized, at least not as long as the matrix lacks more informational weight, as e.g. in That Bill is intelligent she thought only for a short moment. Ross (1973) invoked for this purpose a rule of that-deletion that is built into his Slifting transformation. ${ }^{33}$ If (18a) is analyzed accordingly, we need to know why the requirement of informational weight should be missing here. In fact, a lack of informational weight seems to be more or less required there. Finally, as (22b) demonstrates, the purported matrix may follow something that can only have an unembedded status due to the fact that is represents direct speech. Taken together, these observations signal that in sentences like $(18 \mathrm{a}, \mathrm{b})$ the first clause is a matrix clause and the part that follows is, in all likelihood, a parenthetical. The fact that these parts can "float" through the sentence, suggests that this is a plausible possibility: ${ }^{34}$

(23) a. Bill has played, \{I guess / she thought / we believe $\}$, a major role in this affair b. What would, do you think, Ben's brother say about our proposal? 
I don't want to deny that the parenthetical has ultimately emerged from a matrix clause. Ross (1973) has given a number of good arguments to this extent. The derivation of the parenthetical from a matrix clause by IP-raising/Slifting as a productive process is yet another matter. The main reservation against a straight movement analysis is that the preposed clause does not seem to have retained its subordinate nature. Reconstruction in its purported trace position is out of the question. Thus, if the only tangible data that could support local IPmovement require a solution that differs from a regular movement analysis, Koopman's analysis of intonational yes/no questions in (17b) and of the Slifting cases in (18) must be met with reservation.

I conclude from this that no convincing argument in favor of IP-movement, not even local IP-movement has been provided so far, and that analyses which assume it for theoryinternal reasons have to be supplemented with various additional assumptions in order to cope with problems of the sort mentioned above.

\section{MOVEMENT FROM SpecCP?}

Chomsky (1986:26) discusses Spanish examples provided by Esther Torrego in which it seems that extraction has taken place from a phrase in SpecCP.

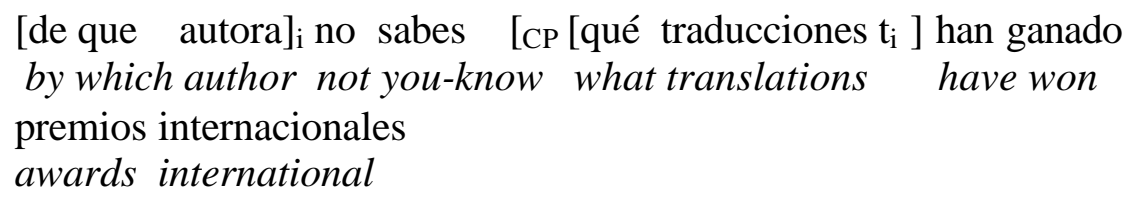

On the basis of such examples, Chomsky assumed within the Barriers framework that the specifier of $\mathrm{CP}$ can be ?-governed by the matrix verb and consequentially ceases to be a barrier. As Sternefeld (1991: 121ff) points out, this theoretical conclusion rests, in all likelihood, on a misanalysis of the example. Obviously, the phrase de que autora belongs to the matrix predicate and does not necessarily associate with a trace in the phrase in SpecCP. Sternefeld points out that the Spanish speakers he asked found (24) either incomprehensible, or they interpreted the phrase de que autora as part of the matrix clause. He also notices that the German equivalent of (24) is grammatical, while the following examples are not:

*Von welcher Autorin fragtest du, welche Übersetzungen Preise gewannen? by which author asked you what translations awards won

(26) *Von welcher Autorin hast du vergessen, welche Übersetzungen Preise gewannen? by which author have you forgotten what translations awards won

The reason is that the von-PP disallows a lexical construal with fragen or vergessen. Other cases of German which amount to the same or a comparable constellation are invariably deviant. The following examples involving topicalization and wh-movement are drawn from Müller (1997):

(27) a. [Über wen $]_{\mathrm{i}}$ meinst du [CP $\mathrm{t}_{\mathrm{i}}^{\prime}$ [hat der Fritz [NP ein Buch $\mathrm{t}_{\mathrm{i}}$ ] geschrieben? about who think you has the Fritz a book written 


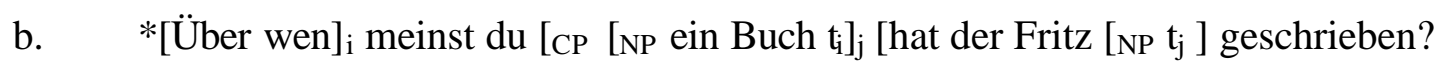

(28) a. [Worüber $]_{i}$ hast du [NP was für Bücher $\left.t_{i}\right]$ gelesen?

what-about have you what for books read

b. $\quad *[\text { Worüber }]_{\mathrm{i}}$ hast du gesagt $\left[\mathrm{CP}\left[\mathrm{NP} \text { was für Bücher } \mathrm{t}_{\mathrm{i}}\right]_{\mathrm{j}}\right.$ er $\left[\mathrm{NP}_{\mathrm{j}} \mathrm{t}_{\mathrm{j}}\right]$ gelesen hat? what-about have you said what for books he read has

(27a) shows that extraction from an NP (with a weak determiner such as ein) is possible, but in (27b) extraction is blocked because the NP has been topicalized. The data in (28) show the same with respect to wh-movement. ${ }^{35}$ The judgements are Fiengo et al.'s. (ia) shows that extraction from the subject position is bad, as expected; in (ib) the situation seems to improve due to the fact that the extraction site is now in SpecCP. (ii) shows that extraction is somehow still possible from a phrase that has been topicalized. Although the main concern of Fiengo et al. is LF-movement, they take such examples of overt movement as indicative of the fact that subextraction from material in an $\mathrm{A}^{\prime}$-position is possible at LF, and that this has to be implemented as adjunction to the dominating phrase. According to their proposal, adjunction, the prerequisite of classical QR-style LF-movement, is only possible to non-arguments (cf. the original idea of this in Chomsky, 1986), and since A'-moved XPs are non-arguments, any such phrase is predicted to lose its barrier satus. With some of the assumptions of the Barriers theory gone, I confine myself to acknowledging that the contrasts in (i) and (ii) have to be explained somehow. But since even the bexamples are far from fully grammatical, according to Ian Roberts (p.c.) in fact "quite bad", the relevance of these cases for my argumentation will be marginal.

As for LF-movement/absorption we can observe two types of data, one type in which absorption seems to proceed from SpecCP without problem, and one type in which it is seriously affected by topicalization and scrambling. In English as well as in German, the following cases of LF-movement/absorption seem to be fine.

(29) Who had forgotten [[which picture of who $]_{i}\left[\right.$ we have bought $\left.\left.t_{i}\right]\right]$ ?

(30) Wer hat vergessen [[welche Bilder von wem $]_{i}(\mathrm{da})$ [wir $t_{i}$ gekauft haben]]?

The following cases of topicalization and scrambling are clearly deviant. ${ }^{36}$

(31) *Who had forgotten [that [picture of who $]_{i}\left[\right.$ we have bought $\left.t_{i}\right]$ ?

(32) *Wer hat vergessen [daß [Bilder von wem $]_{i}\left[\right.$ kein Mensch $t_{i}$ gekauft hat]]? who has forgotten that pictures of who no person bought has

(31) and (32) become, of course, fully acceptable, if the moved phrase is put back into its trace position. This suggests that the wh-in-situ element in (29) and (30) is not absorbed from SpecCP but rather from the base position of the category in which it occurs. That the process is not confined to positions in the IP-domain can be seen in (32) where SpecCP has been activated by a -wh phrase:

*Wer hat gesagt [[Bilder von wem] $]_{i}[$ hätte [er ti gekauft]]?

who has said pictures of who had he bought

We can conclude that whatever the proper syntactic implementation of wh-in-situ licensing is, subextraction or absorption from a phrase XP in an A'-position is not possible unless XP itself is a wh-phrase. ${ }^{37}$ The question remains why reconstruction into the trace position would not rescue the in-situ wh-phrase in (31)-(33). An answer to this would clearly go beyond the 
scope of this article. The right conclusion seems to be that, contrary to Fiengo, Huang, Lasnik and Reinhart (1988), movement to SpecCP, topicalization as well as scrambling of a phrase XP leads to a "freezing" effect according to which XP becomes an island. ${ }^{38}$ This is not only the case for overt movement but, as we have seen, also for covert movement provided that the above mentioned caveat about + wh XPs is respected.

It is not my goal to give an explanation of the freezing effect. I will rather use it as a diagnostic. The prediction is that if clauses with FCs are derived by raising IP into the specifier of an underlyingly IC as shown in (8), the same ban on movement from SpecCP should hold. As a matter of fact, however, both Indo-Aryan and Dravidian languages can be shown to permit overt as well as covert movement from FC-clauses. Consider first the data from Bengali in (34) and from Malayalam in (35). ${ }^{39}$

(34) a. [tomar beral-ke $]_{\mathrm{i}}$ amra SObai $\left[\mathrm{paS}-\mathrm{er}\right.$ baRi $-\mathrm{r}$ kukur $\mathrm{t}_{\mathrm{i}}$ your cat -ACC we all side-GEN house-GEN dog kamRe-che bole] Sune-chilam

bite -PTS3 COMP hear-PTS1

"Your cat, we have all heard that the dog from next door has bitten"

b. [bas theke $]_{i}$ amar didi [Otogulo duronto bacca $t_{i}$ bus from my sister so-many uncontrollable children laphi-ye nam -be bole] bhabe ni jump-PPT descend-FUT3 COMP think3 NEG-PTS

"From the bus, my sister didn't think that so many uncontrollable children would jump off"

(35) [aa kulatt-il $]_{\mathrm{i}}$ ayaal [waliya miinu-kal $\mathrm{t}_{\mathrm{i}}$ unt? enn? ] paraññu that pond-LOC he big fish-PL is COMP said

"In that pond, he said there are big fish"

In both cases, a constituent has been extracted from a CP which is headed by a FC. Similar examples from Japanese are quoted in Grewendorf and Sabel (to appear).

Consider next the following examples from Bengali and Marathi:

ora [[ke aS -be $]$ bole $]$ Sune-che they who come-FUT3 COMP hear-PTS3

i. "They have heard who will come" (narrow scope of ke)

ii. "Who have they heard will come?" (wide scope of $k e$ )

(37) Minila [Lilini Ravila kay dila asa] vatta

Mini Lili to-Ravi what gave COMP believes

"What does Mini believe that Lili gave to Ravi?"

(Wali, 1988)

(36) is ambiguous with respect to the scope of the interrogative operator $k e$ because the matrix predicate allows both construals. The matrix predicate in (37) allows only a wide scope construal of kay. Similarly, Mahajan (1990:160) provides examples from Hindi which show that a wh-operator inside a clause headed by the FC ke liye may obtain scope over the matrix clause as long as the clauses headed by ke liye is not extraposed. See also Savio (1991) for Tamil and various other observations converging on the same picture. In all these cases we must assume covert movement of an operator from an FC-clause to the matrix clause. But given the general ban on movement of and subextraction from phrases in SpecCP, this is in immediate disagreement with the analysis offered in (8). ${ }^{40}$ 
The problem is voided under the more traditional assumption that, as a consequence of parametric choice, languages may have a truly head-final order of constituents, and that the complementizers we find in these languages are genuine FCs. In that case, extraction can proceed as it does in the European languages with an articulated functional periphery at the left edge of CP. Of course, we are far away from a theory of movement that would do justice to the movement processes in rigid and in hybrid SOV-languages. For simplicity, I assume here that despite the fact that a filled SpecCP-position is normally not observed in wh-in-situ languages, such a position can be activated for the derivation of long distance dependenc ies.

As Kayne (1994) observes, head-final languages normally do not show wh-movement, and so far no languages have been found which show wh-movement to the right. The reason for this seems to be that the only choice that UG offers is the spec-head-complement articulation Kayne argues for. If we have succeeded so far in showing that FC-clauses cannot be the result of IP-raising to the left of an IC, Kayne's universal order hypothesis could be weakened to the claim that the order head-spec is excluded at the PF-side of the grammar. There is indeed evidence from wh-movement in American Sign Language (ASL) which addresses this point. As Neidle, Kegl, Bahan, Aarons and MacLaughlin (1997) show, ASL has whmovement to the right, i.e. to the final temporal space in the series of hand movements, a space in which non-wh elements are otherwise not found, and that the scope of the whoperator is signalled by sustained non-manual marking (e.g. raised eyebrows). This suggests that the spec-first ordering is forced by the language-external medium in which syntactic structures are linearized. ${ }^{41}$ Phonetically articulated language may be subject to different constraints on ordering than language which is expressed by a different medium. If this is so, the ban against head-spec ordering may be absent in languages in which spec is only abstractly activated in order to host an intermediate trace.

Ignoring differences that may arise from distinct types of movement (A- vs. A'-movement, scrambling) and also ignoring the overt/covert distinction, extraction from FC-clauses seems to be best captured as shown in (38).

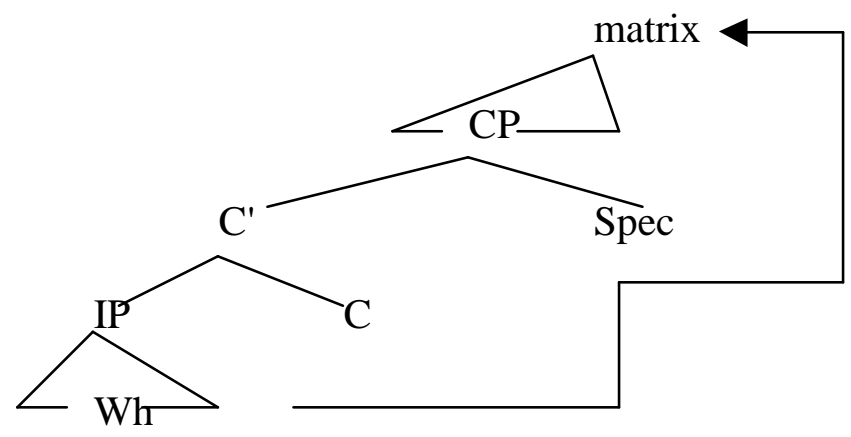

Since topicalization is manifested in visible syntax, the landing site to the left of the FCclause as in (34) and (35) is expected. The abstract trans-clausal movement of the whoperator that must be assumed in (36ii) and (37) may be subject to different restrictions on order. Alphonce and Davis (1997), arguing from the viewpoint of parsing, assume that wh-insitu induces a gap-creating rather than a gap-filling process, and that, as a consequence, the filler will in this case follow the gap in this case.

Although the present considerations of trans-clausal movement from FC-clauses had to remain sketchy, they should have made it clear that the complement-head articulation of FCCPs is underived, and that as a consequence languages which have FC- as well as IC-clauses have to be considered irreducibly hybrid. 


\section{THE POSITION OF CP}

The attentive reader will have noticed in the examples presented so far IC-clauses and FCclauses were pretty much in complementary distribution with respect to the order between $\mathrm{V}$ and CP. Although we cannot be sure about the full range of ordering possibilities, the gross generalization seems to be that in head-final languages IC-CPs always stay to the right of a licensing head ( $\mathrm{N}$ or $\mathrm{V}$ ), while FC-CPs (almost) always stay to the left of a licensing head. ${ }^{42}$ Under the assumptions of a universal spec-head-complement order, any clausal complement will be merged to the right of $\mathrm{V}$ and will then either undergo leftward movement or remain in situ. The Bengali example (11a), which I represent with glosses for convenience must then be derived as in (39).

(i) base

BOY - HEAR - [C [FATHER COME]]

(ii) strong features in $\mathrm{C}$ force movement of the embedded IP to SpecCP:

BOY - HEAR - [[FATHER COME $\left.]_{i}\left[\mathbf{C}\left[\mathrm{t}_{\mathrm{i}}\right]\right]\right]$

(iii) strong features in some zero head $\mathrm{H}$ to the left of $\mathrm{V}$ force movement of the newly formed $\mathrm{CP}$ to the specifier of $\mathrm{H}$ :

BOY - [[FATHER COME $\left.]_{\mathrm{i}}\left[\mathbf{C}\left[\mathrm{t}_{\mathrm{i}}\right]\right]\right]_{\mathrm{j}}-\mathrm{HEAR}-\left[\mathrm{t}_{\mathrm{j}}\right]$

We have already criticized that the account of surface word order in terms of feature strength remains without independent motivation, but let us ignore this now. According to the Minimalist Program, non- movement of a category means "procrastinated" movement i.e., if a structure does not undergo movement before Spell-Out, it has to undergo move ment postSpell-Out. Post Spell-Out movement would then be implemented as Move-F. I would like to consider cases now which create a problem for a theory that combines standard Minimalist assumptions with a universally valid LCA à la Kayne (1994). The point is simply and straightforwardly that IC-clauses, which - as we have seen - arise to the right of the verb, fail to undergo overt as well as covert movement.

Consider first the observation that overt movement of IC-CPs is not grammatical in any language from the group of hybrid languages that I am talking about. Here are examples from Bengali:

$$
\begin{aligned}
& \text { a. chele-Ta Sune-che [je [or baba aS -be]] } \\
& \text { boy-CF hear-PTS3 COMP his father come-FUT3 } \\
& \text { b. } \quad \text { [je [or baba aS-be]] chele-Ta Sune-che } \\
& \text { c. *chele-Ta [je [or baba aS-be]] Sune-che }
\end{aligned}
$$

(40a) would be the base form; (40b) would be a case of topicalization, and (40c) would be a case of $\mathrm{CP}$-scrambling. Both topicalization and scrambling are perfectly normal operation in Bengali and related languages as long as the moved constituent arises to the left of the verb. Thus, there must be a deep reason why $(40 \mathrm{~b}, \mathrm{c})$ are ungrammatical, and why the clause headed by je is firmly stuck to the right of the verb. It could, in principle, undergo movement if we assume that it was attracted by a feature that triggers topicalization. But even under this condition, movement of a je-clause to the left is impossible. According to my inquiries, the same is true for Hindi, Marathi and also Turkish $k i$-clauses. They are all confined to the right 
periphery and don't have any status to the left of the verb i.e., where arguments normally line up in these languages. This gives rise to doubts whether any clause at all can move from the position to the right of the verb. If these doubts are on the right track, the derivation shown in (39) may be impossible for principled reasons. The LCA-based theory has to formulate a reason why certain clauses undergo leftward movement while others remain in situ. A theory that accepts a limited range of irreducible word order hybridity must, of course, come up with an explanation too, but it has an advantage: It can use the ordering of IC-clauses which is "exceptional" with respect to the undeniable head final nature of the language. ${ }^{43}$ For the LCAbased theory the observed order of IC-CPs is the only basic order the theory admits; thus, it cannot be "exceptional", and an independent reason for the immobility of IC-CPs has to be found.

This leads to my second point: Covert movement. According to Chomsky (1995) (but not necessarily according to Kayne, 1994), a category that did not undergo movement to a licensing position before Spell-Out (PF) has to do so after Spell-Out, i.e. at LF. Whether procrastinated movement should be implemented as Move- or as Move-F is irrelevant here. My point is that an IC-CP would have to undergo raising at some point in the derivation in order to check formal features (such as Case features) associated with the predicate. But if such raising can, in principle, occur, we expect that it can always occur if there is a reason for movement. Such a reason is, of course, given where CP is quantified and has to undergo movement to an operator position to the left of the matrix predicate. A CP can be quantified by a focus particle such as only or even. As the following Turkish data show, however, ICCPs quantified with only are out: ${ }^{44}$

(41) a. [sadece [Hasan- i da davet ed-er -se -n]

only Hasan-ACC also invite -AOR-CON-2SG

yemeg -e gel -eceg-iz

dinner-DAT come-FUT-1PL

"Only if you invite Hasan too, will we come for dinner"

b. Ben sadece iste - di - $\mathrm{m}$ [ki [birileri ben-i karsila-sin]]

I only want-PTS-1SG KI someone I -ACC pick-up-OPT

"I only wanted that someone picks me up"

c. *Ben iste-di-m [sadece [ki [birileri ben-i karsila-sin]]]

(41a) shows that the operator sadece can quantify a clause; (41b) shows that this operator can affect the embedded CP - now one of the notorious IC-CPs initiated by $k i$, but only at a distance i.e., where the operator "binds" the affected phrase without forming a constituent with it. I assume that the operator is here in a designated head position associated with the matrix predicate. The interesting case is (41c) where sadece forms a constituents with the $k i$ clause. Following the pattern seen in (41b), one could expect that the quantified CP sadece $k i$ birileri ben-i karsila-sin will undergo LF-movement to the specifier of a particle phrase PrtP of the matrix clause, as suggested in Bayer (1996). This is expected under the central assumptions of the Antisymmetry hypothesis. According to the universal head-complement order, the $k i$-clause is in its basic position. It is rather unexpected then that the presence of sadece would cause ungrammaticality.

This is by no means an isolated fact. It is, for instance, also true for Bengali which, as we have seen, also has a type of finite clausal complement that can only appear to the right of the matrix verb. In (42a), the particle Sudhu ("only") is likely to be in the head position of the functionally defined phrase PrtP. As (42b) shows, Sudhu can also occur as a co-constituent of 
an XP. This second option is taken in (42c) in which Sudhu forms a constituent with CP. (42c), however, was rejected by all the speakers I consulted.

(42) a. SEmoli Sudhu bhebe-che [je ami rObindro SONgit

Shyamali only think-PTS3 that I Rabindra song

pocchondo kor-i na]

like do-1 NEG

"Syamali only thought that I dislike songs by Rabindranath Tagore"

b. SEmoli bhebe-che [je [Sudhu ami] rObindro SONgit

Shyamali think-PTS3 that only I Rabindra song

pocchondo kor-i na]

like do-1 NEG

"Syamali thought that only I dislike songs by Rabindranath Tagore"

c. $\quad *$ SEmoli bhebeche [Sudhu [je ami rObindro SONgit pocchondo kori na]] intended: "Syamali thought [only [that I dislike songs by

Rabindranath Tagore]]"

The most natural explanation of the status of (42c) seems to be that LF movement from the right of the verb is as impossible as overt movement from this position. In that case, (42c) would be ruled out in the same way as (41c) as a violation of the Principle of Full Interpretation: Sudhu as well as sadece cannot be interpreted where they arise, and movement to a licensing position (to the left of the matrix predicate) is blocked because the quantified CP is parametrically on the "wrong" side of the verb. It is important to see that Sudhu can be construed with a CP. This is shown by the following data:

a. SEmoli [Sudhu [ami rObindro SONgit pocchondo kor-i na bole]]

Shyamali only I Rabindra song like do-1 NEG BOLE

bhebe-che. SEmoli ar kichu -i bhab-e ni

think-PTS3 Shymali further anything-at all think-3 NEG-PTS

"Syamali only thought that I dislike songs by Rabindranath Tagore. Shyamali did not think anything else"

b. SEmoli [Sudhu [agami bochor kolkata-y aS -be bole]]

Shyamali only coming year Calcutta-LOC come-3FUT BOLE

jani -e -che. Se ar kichu -i jan -a -e ni

know-CAUS-3PTS she further anything-at all know-CAUS-3 NEG-PTS

"Shyamali let (us) know only that she would come to Calcutta next year. She didn't let (us) know anything else"

Here the bole-CP is generated to the left of the matrix verb i.e., in the canonical position of a Bengali object. From this position, the entire quantified CP can undergo LF-movement to a position where Sudhu can take matrix clausal scope. This underlines my point in connection with (42c). In (42c), we see a deviation from the canonical object position. This deviation has created a structure that blocks LF-movement. In (43a,b), strict canonicity of the object position is retained, and we see that LF-movement is permitted. What would the theory of universal head-initiality make us expect? Since according to this theory, the IC-CP arises to the right of the verb and is by default in "canonical" position, we would at best expect the opposite to be true: In terms of GB-theory or the Barriers framework, extraction from a 
phrase XP presupposes that XP be governed (or L-marked). If we extend this generalization to those cases where extraction of XP itself is concerned, we would expect that XP moves from its basic position, but - due to the freezing effect - not from a derived position. For the languages under discussion, the conclusion seems to be rather unavoidable that the basic position of a CP-complement is to the left of V. Clauses which are "exceptional" in these languages by having an IC instead of an FC, are "exceptionally" positioned at the right periphery of the verb. For reasons that I have specified in Bayer (1996) and which are incompatible with central assumptions of the Antisymmetry hypothesis, such clauses are severely restric ted with respect to movement. ${ }^{45}$

Let me finally return to an aspect that had already been referred to in section 3.3. Assuming with Klaiman (1977) that the FC is a postposition, and also assuming that postpositions may serve as Case particles, it could be expected that the step from (39ii) to (39iii) occurs as a consequence of Case checking. ${ }^{46}$ The FC bole would then be a Case particle in disguise. While a Case explanation would provide a reason for the preverbal positioning of boleclauses, this would, of course, not yield the CP-raising analysis suggested by the LCA. To substantiate this, let me introduce a type of bole-clauses that Singh (1980) refers to and that had been ignored so far. As (44) shows, bole can be the head of a purpose clause, and in this case the awkwardness of the bole clause in right peripheral position is absent:

ami ekhane eSe -chi [[tomar SONge kOtha bolbo] bole]

I here come-PTS1 you with speech say-FUT1 BOLE

I have come here in order to talk with you

If we do not want to assume different homophonous lexical heads for argument and adjunct clauses, a step that should be avoided for independent reasons, a Case explanation of the positioning of bole clauses has difficulties explaining how the $\mathrm{CP}$ in (44) can be licensed. One cannot argue that only argumental bole-CPs would undergo leftward movement; purpose clauses with the bole-CP in preverbal position(s) such as ami ekhane [[tomar SONge kOtha bolbo] bole] eSechi are just as acceptable as (44). Thus, whatever can be made of a Case licensing explanation of FC-clauses, the result will be neutral with respect to the main issue of this section, namely the basicness or typological exceptionality of $\mathrm{V}-\mathrm{CP}$-order. As we have shown, the assumption of this order and subsequent CP-raising or LF-movement of (features of) CP leads to serious problems. These problems can be avoided under the assumption that natural language grammars can tolerate word order hybridity.

\section{SUMMARY AND CONCLUSIONS}

The question that has been addressed in this article was: Is there a syntactically uniform class of complementizers according to which a given language permits one and only one order between $\mathrm{C}$ and IP, or is it possible that a language shows irreducible hybridity such that the order between C and IP is to a certain extent free. In the cases at hand "to a certain extent" means that [C IP] and [IP C] would coexist, but that they would do so with non-overlapping sets of complementizers for each of the two linearizations. Recent developments in generative grammar initiated by Kayne (1994) narrow the choices down to a single one: Since UG permits spec-head-complement as the only possible order, the only permissible order of $\mathrm{C}$ and IP would be [C IP], i.e. C would underlyingly always be an initial complementizer (IC); the order observed in [IP C] must then be derived, i.e. a final complementizer (FC) would actually be a hidden IC. And since according to this theory UG restricts 
movement to leftward movement, the latter order must come about by raising of IP to the left of C.

On the basis of a closer inspection of languages which I called "hybrid" due to the fact that their CPs exhibit both orders, I came to the conclusion that the derivation of FC-clauses by IP-raising is not tenable. The arguments were the following:

A. If FCs were ICs in disguise, we would expect to see in one and the same language or in closely related languages or dialects CPs which differ from [IP C] only by the fact that IP has failed to undergo raising. As a matter of fact, however, the complementizers involved in the variation at hand are never the same lexical items: Among the South Asian languages, ICs are either borrowed or coined after an alien model as seems to be the case for the widespread element $k i$, or they coincide with the relativizer $j e$. FCs, on the other hand, are almost invariably grammaticalized verbal forms which derive from verba dicendi. Thus, it is highly unlikely that ICs and FCs form a lexical class, and that the difference would be captured by the application or non-application of IP-movement.

B. No convincing morphological or syntactic reason has been found which would motivate IP-movement to the left (to the specifier of an IC in disguise). The IPs involved in Bengali cases of complementation are the same for IC- and for FC-clauses. Thus, leftward movement cannot be driven by the internal structure of the IP involved. Similarly, no convincing reason could be found for the claim that certain Cs surface as FCs because they are affixal, and that IP raises in order to "rescue" them from a crash at PF (the articulatory-perceptual interface in Chomsky, 1995).

C. "Long" IP-movement with a stranded C has obviously never been observed. But even strictly local movement of IP to SpecCP as assumed by Kayne (1994) (or to some higher Spec as assumed by Koopman (1995)) is not empirically well-supported. As far as I can see, its status is entirely hypothetical and dependent on the theory that demands it.

D. Facts from languages with a more articulate left clausal periphery than the South Asian languages indicate that phonetically spelled-out material in SpecCP is immune to further movement. German shows this quite clearly for both overt and covert movement. If FCclauses rest on a derivation that moves IP to SpecCP, it can be expected that similar restrictions will hold. Contrary to this expectation, however, the IPs in FC-clauses are free of such restrictions. Both overt and covert movement is attested.

E. If UG provides only the basic order (spec)-head-complement, a clausal complement in a head-final language has to be raised to the left of V. In a language which shows both IC- and FC-clauses, and in which CPs do not always undergo raising, structures like [V [IP C]] and [[C IP] V] could be expected. In fact, however, these do not seem to occur and are felt by native speakers to be deviant. The judgements are especially clear for [[C IP] V] or any other structure in which the IC-clause is further to the left of $\mathrm{V}$. This finding holds again for both overt and covert movement. The complementary positioning of "governed" FC- and ICclauses to the left and to the right of $\mathrm{V}$ respectively invites the null-hypothesis that nothing moves at all, and that both are exactly generated where we see them.

If these arguments are sound, it follows that in those languages in which it is observed, hybridity in the order between head and complement may be irreducible. Notice that hybridity should not in general be a surprising phenomenon. German is a good example of a grammar with "mixed" head-complement order: With the exception of CPs, the arguments of $\mathrm{V}$ appear to the left of $\mathrm{V}$, and the language has predominantly prepositions rather than 
postpositions; certain PPs may occur on either side of $\mathrm{V}$ or $\mathrm{A}$; in $\mathrm{V}$-final clauses, I (or the complex of functional elements that constitute I ) follows the VP, while in the DP D precedes NP. ${ }^{47}$

It has been claimed that languages may pass through historical stages which do not permit the learner to converge on a single parameter for a certain domain. Santorini (1992; 1993) gives evidence from the development of Yiddish that points in precisely this direction. ${ }^{48}$ According to Santorini's findings, it must be possible that VO/INFL-medial and OV/INFL-final order both belong to the grammar of a single speaker, and that the "adaptive" rules that would be needed to map the different surface orders to a single base would be "highly idiosyncratic devices". The alternative is according to her the "double base hypothesis" which she characterizes as follows:

"This hypothesis is based on the assumption that children have the ability to abduct more than one grammatical system from the primary data in the course of acquisition - an ability for which the phenomena of multilingualism, diglossia and intrasentential code-switching provide independent and incontrovertible evidence." 49

If the language learning child can abduct a grammar on the basis of more than one elementary order between head and complement for the same lexical or functional heads, then the acquisition and parameter setting problem that is implied by my conclusions should be comparatively small. Recall that the difference between IC and FC in the languages under discussion is always accompanied by an immediate lexical difference. ICs and FCs are not solely distinguished on a positional basis, but in addition by the fact that ICs are invariably $k i$ or je while FCs are invariably bole, boli, buli, asa, mha un, te etc. If UG permits the simultaneous development of syntactic phrases which are heterogeneous with respect to a certain value, it should be easy for the child to do so on the basis of overt morpho-lexical triggers. The more interesting question seems to be how the child finds out what the dominating parameter of his/her language is, for instance, how the Bengali child finds out that Bengali is head-final despite the fact that there are je-clauses, which happen to be $\mathrm{C}$ initial and occur only in the context to the right of the verb that selects the clause. Given the fact that all the languages under discussion are almost purely head-final, IC-clauses will certainly not trigger an initial setting of a binary word order parameter that regulates the order between head and complement. In the same vein, the fact that IC-clauses follow rather than precede the verb will not suppress the setting of a basic order for $\mathrm{V}$ in relation to its complement(s) as may be the case in Yiddish. Since IC-clauses retain a host of distinctive qualities, they will easily be incorporated into the grammar with a special status. ${ }^{50}$

My discussion naturally leads to the question why and how languages develop hybrid systems of this sort. A full answer would go beyond both the scope of this article and my diachronic and sociolinguistic competence. One piece of evidence that cannot be ignored by anyone, however, is the geographical map that corresponds to the IC/FC-distribution: Northwestern Indo-Aryan languages on the Indian subcontinent that have no border with Dravidian (Standard Hindi, Kashmiri, Punjabi etc.) have predominantly or exclusively ICs. Eastern Indo-Aryan languages and languages which border on Dravidian territory (Oriya, Bengali, Assamese, Marathi, Dakkhini Hindi etc.) have in addition FCs. Semantically bleached-out verbs of speaking functioning as FCs are a core property of Dravidian; thus, it is not too surprising to see them in the geographically adjacent Indo-Aryan languages. However, the formation of the South-Asian Sprachbund in which complementizers and their grammar play a role, required more than the exchange of lexical items. According to Masica (1994), it can only be the result of multiple factors such as bilingualism, shared culture and shared history as well as a combination of convergent grammatical features. ${ }^{51}$ The German 
linguistic tradition as represented by Hermann Paul ascribes the emergence of what is somewhat metaphysically called innere Sprachform at least partially to grammatical assimilation induced by language contact. ${ }^{52}$ While I cannot go into this in any more detail, I hope to have convinced the reader that the problem cases discussed in this article cannot be captured in an enlightening way by a mechanical reduction of the parametrical space of variation we may encounter within a single language.

\section{APPENDIX: A Note on the Origin of $j e$ and bole in Bengali}

Looking at the Bengali $\mathrm{C}$-system from a diachronic perspective, the modern situation is quite transparent: $J e$ is originally (as well a synchronically) a relativizer. Relativizers - for some reason - strongly tend to undergo movement to SpecCP, despite the fact that Bengali is largely a Wh-in-situ language. In contrast to the so-called "correlative" relative clauses, $j$ relatives appear to the right of a nominal head. ${ }^{53} \mathrm{Cf}$. Bayer (1996: ch.7) for a detailed discussion of dependent clausal licensing in Bengali. Assuming that $j e$ has been reanalyzed as a complementizer, as argue in Bayer (1996), it is natural that it has kept its linear position at the left edge of the CP. As has been pointed out in the article, in contrast to FCs in languages like Marathi, the Bengali and Hindi $j e$ and $k i$ are something like "wild card" subordinators. Alice Davison (p.c.) suggests that the only feature they are sensitive to seems to be T(ENSE). According to her, there may then be a reason behind the choice of $j e$ as a complementizer in Bengali, namely that - being originally a relativizer - it is semantically incompatible with interrogative features and has therefore developed into a functional head which is insensitive to interrogative features. In addition, Bengali $j$-relativizers are only compatible with tensed IPs. Thus, it is not surprising after all to see $j e$ in the role of an initial complementizer that heads tensed CPs which are stuck in "extraposed" position. It appears that many (initial) complementizers of the better known Indoeuropean Western languages are decayed operators. In this general scenario, then, the emergence of Bengali $j e$ as a complementizer loses its "exotic" flavor.

The origin of bole seems to have been completely different; bole being homophono us with the participial form "having said" has its natural place where verbs appear in Bengali, namely at the right edge of the clause. From this perspective it is rather idle to hope for evidence that bole could have been an initial head at some historical stage of the language. Referring to earlier work by Yamuna Kachru which was not available to me, Singh (1980) compares Bengali bole with the Sanskrit quotative marker iti. He notes that bole cannot be used in all contexts in which an initial complementizer could be used. Notice, for instance, the following:

(i) tumi kolkata ja -cch -o bole $\{*$ dekh-1 - am / Sun-1 - am / jan -1 -am $\}$ you Calcutta go-PROG-2 BOLE see-PTS-1 / hear-PTS-1 / know-PTS-1 "I $\{$ *saw / heard / came to know $\}$ you were going to Calcutta"

Bole cannot be used with "see", while je would not have this restriction. A glance at the ancestors of Bengali shows that this reflects the quotative character of bole. Following Hock (1982), Saxena (1995) points out that the Sanskrit quotative iti has gradually expanded its functions over time. In the oldest documents of the Rig Veda (1500-900 B.C.), iti was used as a direct quote marker in the contexts of the verbs for asking and thinking. In the Atharva 
Veda the use of iti increases, and it can now also occur with the verbs "know", "hear" and "fear", and it starts functioning as a purpose marker. In the Vedic prose iti also occurs in dependent clauses in subjunctive mood. Witness the example from Saxena (1995: 365):

(ii) yajñám ... tanavai iti tásmad adityám carúm nírvapati sacrifice spread-SUBJ thus therefore Aditya pot-for-oblation perform-3SG "(Because/thinking) "I will ... spread the sacrifice" therefore he prepares the Aditya pap"

In Classical Sanskrit the function of iti is even more expanded; according to Saxena it is at this period used as a complementizer with verbs like "say", "know", "think", "believe", "wish", and also as a purpose and as a reason marker, but not with "see". The parallel between iti and bole cannot be overlooked. As we have seen, bole also appears in modern Bengali as a reason marker and, as Singh (1980) points out, in a number of other functions which do not overlap with the functions of $j e$-clauses.

\section{ACKNOWLEDGEMENTS}

Part of the material in this article has been presented at the 1995 Tilburg Conference on Final Heads. I wish to thank the audience, in particular Riny Huybregts, Hans-Peter Kolb, Masayuki Oishi and Shigeo Tonoike for discussion and for suggestions which improved this article. Thanks also to Jogamaya Bayer, Tanmoy Bhattacharya, Probal Dasgupta, M.T. Hany Babu, Tom Güldemann, Hubert Haider, Jaklin Kornfilt, Marga Reis, Ian Roberts, Joachim Sabel, Rajendra Singh, Peter Suchsland, and to two anonymous reviewers for valuable suggestions, help with the language data and literature. Special thanks to Alice Davison for detailed written comments and for her readiness to discuss problems of South Asian syntax with me. Of course, I take the responsibility for any remaining errors. 


\section{REFERENCES}

Alphonce, C. and H. Davis: 1997, "Motivating non-directional movement," in D. Beerman,

D. LeBlanc and $\mathrm{H}$. van Riemsdijk (eds.), Rightward Movement, John Benjamins, Amsterdam.

Arora, H.: 1985, Some Aspects of Dakkhini Hindi-Urdu Syntax with Special Reference to Convergence, Doctoral dissertation, Delhi University.

Bal, B.K.: 1990, COMP and Complementizers in Oriya and English, Doctoral dissertation, Central Institute of English and Foreign Languages, Hyderabad (India).

Bayer, J.: 1995, "On the origin of sentential arguments in German and Bengali," in H. Haider, S. Olsen and S. Vikner (eds.) Studies in Comparative Germanic Syntax. Kluwer, Dordrecht.

Bayer, J.: 1996, Directionality and Logical Form: On the Scope of Focussing Particles and Wh-in-situ, Kluwer, Dordrecht.

Bayer, J. and A. Lahiri: 1990, "Bengali emphatic clitics in the lexicon-syntax inter-face," in W. U. Dressler, H.-C. Luschützky, O. Pfeiffer and J. Rennison (eds.), Contemporary Morphology, Mouton de Gruyter, Berlin.

Bhatt, R.: 1993, Word Order and Case in Kashmiri, Doctoral dissertation, University of Illinois at Urbana-Champaign.

Bhatt, R. and J. Yoon: 1991, "On the composition of COMP and parameters of V2,", Paper presented at WCCFL 10, March 2, 1991.

Browning, M.: 1996, "CP-recursion and that-t effects," Linguistic Inquiry 27, 237-255.

Chatterjee, S.K.: 1926, The Origin and Development of the Bengali Language, 3 vols., Calcutta University Press, Calcutta, [reprinted 1975, Rupa \& Co., Calcutta].

Chomsky, N.: 1981, Lectures on Government and Binding, Foris, Dordrecht.

Chomsky, N.: 1986, Barriers, MIT Press, Cambridge, Massachusetts.

Chomsky, N.: 1991, "Some notes on economy of derivation and representation," in R. Freidin (ed.), Principles and Parameters in Comparative Grammar, MIT Press, Cambridge, Massachusetts. [also in Chomsky, 1995]

Chomsky, N.: 1993, "A minimalist program for linguistic theory," in K. Hale and S.J. Keyser (eds.), The View From Building 20: Essays in Linguistics in Honor of Sylvain Bromberger, MIT Press, Cambridge, Massachusetts. [also in Chomsky, 1995]

Chomsky, N.: 1995, The Minimalist Program. MIT Press, Cambridge, Massachusetts.

Corver, N. and H. van Riemsdijk: 1997, "The position of the head and the domain of scrambling," in B. Palek (ed.), Typology: Prototypes, Item Ordering and Universals. Proceedings of LP '96, Prague, Charles University.

Culicover, P.: Syntax, Academic Press, New York.

Culicover, P.: 1992, "The adverb effect: Evidence against ECP accounts of the that-t effect," NELS 23, vol. 1, 97-111. GLSA, University of Massachusetts, Amherst.

Dasgupta, P.: 1980, Questions and Relative and Complement Clauses in a Bangla Grammar, Ph.D. dissertation, New York University.

Dasgupta, P.: 1983, "Bangla equatives, complementizers, final foci, and roots," Linguistic Analysis 11, 103-137.

Dasgupta, P.: 1984, "Bangla emphasizers and anchors," Indian Linguistics 45, 102-117.

Dasgupta, P.: 1987, "Sentence particles in Bangla," in E. Bashir, M. Deshpande and P. Hook (eds.), Selected Papers from SALA 7, distributed by Indiana University Linguistics Club.

Davison, A.: 1993, "Lexical projection, Case and clause adjunction: Another view of 'Case resistance'," ms. University of Iowa.

Dryer, M.: 1980, "The positional tendencies of sentential noun phrases in universal grammar", The Canadian Journal of Linguistics 25, 123-195. 
Fiengo, R., C.-T.J. Huang, H. Lasnik and T. Reinhart: 1988, "The syntax of Wh-in-situ," in H. Borer (ed.), Proceedings of the 7th West Coast Conference on Formal Linguistics, Stanford.

Gibson, E. and K. Wexler: 1994, "Triggers," Linguistic Inquiry 25, 407-454.

Grewendorf, G. and J. Sabel: 1994, "Scrambling and Incorporation," Linguistic Inquiry 25, 263-308.

Grewendorf, G. and J. Sabel: forthcoming, "Scrambling in German and Japanese: Adjunction $\quad$ versus multiple specifiers," Natural Language and Linguistic Theory.

Grosu, A. and S. Thompson: 1977, "Constraints on the distribution of NP clauses," Language 53, 104-151.

Haider, H.: 1993, Deutsche Syntax - generativ: Vorstudien zur Theorie einer projektiven Grammatik, Narr, Tübingen.

Hawkins, J.: 1990, "A parsing theory of word order universals," Linguistic Inquiry 21, 223261.

Hock, H. H.: 1982, "The Sanskrit quotative: A historical and comparative study," Studies in the Linguistic Sciences 12, 37-96.

Kayne, R.: 1984, Connectedness and Binary Branching, Foris, Dordrecht.

Kayne, R.: 1994, The Antisymmetry of Syntax," MIT Press, Cambridge, Massachusetts.

Kayne, R.: forthcoming, "Overt vs. covert movement," Syntax.

Klaiman, M.: 1977, "Bengali syntax: Possible Dravidian influences," International Journal of Dravidian Linguistics 4.2, 303-317.

Koopman, H.: 1984, The Syntax of Verbs, Foris, Dordrecht.

Koopman, H.: 1995, "The Spec head configuration," ms. UCLA.

Kuno, S.: 1973, "Constraints on internal clauses and sentential subjects," Linguistic Inquiry 4, 363-385.

Lasnik, H.: 1981, "Restricting the theory of transformations: A case study," reprinted in Lasnik, 1990.

Lasnik, H.: 1990, Essays on Restrictiveness and Learnability, Kluwer, Dordrecht.

Lasnik, H.: 1995, "Case and expletives revisited: On Greed and other human failings," Linguistic Inquiry 26, 615-633.

Lust, B., T. Bhatia, J. Gair, V. Sharma and J. Khare: 1995, "Children's acquisition of Hindi anaphora in 'jab clauses': A parameter setting paradox," in V. Gambhir (ed.), The Teaching and Acquisition of South Asian Languages. University of Pennsylvania Press, Philadelphia.

Mahajan, A.: 1990, The A/A-bar Distinction and Movement Theory, Ph.D.dissertation, MIT Cambridge, Massachusetts.

Masica, C.: 1994, "Some new perspectives on South Asia as a Linguistic Area," in A. Davison and F. M. Smith (eds.), Papers from the 15th South Asian Language Analysis (SALA) Roundtable Conference 1993, University of Iowa, Iowa City.

McGregor, R.S.: 1972, Outline of Hindi Grammar, Oxford University Press, Oxford.

May, R.: 1985, Logical Form, MIT Press, Cambridge, Massachusetts.

Müller, G.: 1997, Incomplete Category Fronting, Dordrecht: Kluwer.

Neidle, C., J. Kegl, B. Bahan, D. Aarons and D. MacLaughlin: 1997, "Rightward whmovement in American Sign Language," in D. Beerman, D. LeBlanc and H. van Riemsdijk (eds.), Rightward Movement, John Benjamins, Amsterdam.

Patnaik, M.: 1997, "Some unique features of COMP in selected South Asian languages," hand-out, SALA 18, Jawaharlal Nehru University Delhi, 1997.

Paul, H. [reprinted 1991].: 1975, Prinzipien der Sprachgeschichte, 9th edition of Paul (1880), Niemeyer, Tübingen.

Pintzuk, S.: 1991, Phrase Structures in Competition: Variation and Change in Old English Word Order, Doctoral dissertation, University of Pennsylvania. 
Reis, M.: 1995, "Extractions from verb-second clauses in German?" in U. Lutz and J. Pafel (eds.), On Extraction and Extraposition in German, Benjamins, Amsterdam.

van Riemsdijk, H.: 1978, A Case Study of Syntactic Markedness: The Binding Nature of Prepositional Phrases, Foris, Dordrecht.

Rögnvaldsson, E.: "Word order variation in the VP in Old Icelandic," Working Papers in Scandinavian Syntax 58, 55-86.

von Roncador, M.: 1988, Zwischen direkter und indirekter Rede. Nichtwörtliche direkte Rede, erlebte Rede, logophorische Konstruktionen und Verwandtes, Niemeyer, Tübingen.

Roussou, A.: 1994, The Syntax of Complementisers, Doctoral dissertation, University College London.

Ross, J. R.: 1967, Constraints on Variables in Syntax, Doctoral dissertation, MIT, Cambridge, Massachusetts.

Ross, J. R.: 1973, "Slifting," in M. Gross, M. Halle and Schützenberger (eds.), Formal Analysis of Natural Languages, Mouton.

Sabel, J.: 1997, "Scrambling aus finiten Sätzen: Typologische und universalgrammatische Aspekte, Linguistische Berichte 170, 273-311.

Santorini, B.: 1992, Variation and change in Yiddish subordinate clause word order," Natural Language and Linguistic Theory 4, 595-640.

Santorini, B.: 1993, "Jiddisch als gemischte OV/VO-Sprache," in W. Abraham and J. Bayer (eds.), Dialektsyntax, Westdeutscher Verlag, Opladen.

Savio, D.: 1991, "WH-questions in Tamil," CIEFL Occasional Papers in Linguistics 3, 5567.

Saxena, A.: 1995, "Unidirectional grammaticalization: diachronic and synchronic evidence," Sprachtypologie und Universalienforschung 48. 350-372.

Singh, R.: 1977, "Hindi: COMP-initial or COMP-final?" Montreal Working Papers in Linguistics 1977-78. 203-207.

Singh, U.N.: 1980, "Bole an unresolved problem in Bengali syntax," Indian Linguistics 41. 188-195.

Srivastav, V.: 1991, The syntax and semantic of correlatives. Natural Language and Linguistic Theory 9. 637-686.

Subbarao, K.V.: 1984, Complementation in Hindi, Academic Publications, Delhi.

Subbarao, K.V., H. Arora: 1989, "On extreme convergence: the case of Dakkhini HindiUrdu," in A. Mukherjee (ed.), Language Variation and Language Change, Centre of Advanced Studies in Linguistics, Osmania University, Hyderabad, India.

Subbarao, K.V., C.V. Rao, A. Saxena and N. Rau: 1989, "The verb 'say' in South Asian languages: a study in linguistic convergence," in A. Mukherjee (ed.), Language Variation and Language Change, Centre of Advanced Studies in Linguistics, Osmania University, Hyderabad, India.

Wali, K.: 1988, "A note on WH questions in Marathi and Kashmiri," Cornell Working Papers in Linguistics 8, 161-180.

Wali, K. and O.N. Koul: Kashmiri: A Cognitive-Descriptive Grammar, Routledge, London.

Wali, K. and K.V. Subbarao: 1991, "On pronominal classification: Evidence from Marathi and Telugu," Linguistics 29, 1093-1110.

Wilder, C.: 1988, "On the German infinitival marker $z u$ and the analysis of raising con structions," Lingua 76, 115-175.

Zwart, C.J.-W.: 1997, Morphosyntax of Verb Movement: A Minimalist Approach to Syntax, Kluwer, Dordrecht.

\footnotetext{
${ }^{1}$ Corver and van Riemsdijk (1997) reserve the predicate 'hybrid' for cases where one and the same lexical head may be either final or initial in a language; cases like those treated in the present article, i.e. different lexical heads participating in different ordering relations, are called 'mixed' by Corver and van Riemsdijk.
} 
Unless self-explanatory, the abbreviations used in the glosses are as follows:

\begin{tabular}{|c|c|c|c|}
\hline \multirow{3}{*}{$\begin{array}{l}2 \\
3\end{array}$} & \multicolumn{3}{|c|}{ 1st person (present tense, unless otherwise specified) } \\
\hline & \multirow{2}{*}{\multicolumn{3}{|c|}{$\begin{array}{l}\text { 2nd person (present tense, unless otherwise specified) } \\
\text { 3rd person (present tense, unless otherwise specified) }\end{array}$}} \\
\hline & & & \\
\hline $\mathrm{ACC}$ & accusative & AOR & aorist \\
\hline CAUS & causative & $\mathrm{CF}$ & classifier \\
\hline COMP & complementizer & $\mathrm{CON}$ & conditional \\
\hline DAT & dative & DUB & dubitative \\
\hline ERG & ergative & FUT & future \\
\hline GEN & genitive & LOC & locative \\
\hline MA & verbal suffix & NOM & nominative \\
\hline NEG & negation OPT & & \\
\hline PPT & past participle & PTS & past tense \\
\hline QUOTE & quotative & SG & singular \\
\hline TOP & topic & & \\
\hline
\end{tabular}

${ }^{2}$ In Kayne's more technical presentation, the LCA claims this: $\mathrm{d}(\mathrm{A})$ is a linear ordering of $\mathrm{T}$, where $\mathrm{T}$ is the set of terminals. If $A$ is the maximal set of ordered pairs $X_{j}, Y_{j}$ of nonterminals in a given phrase marker such that for each $\mathrm{j} \mathrm{X}_{\mathrm{j}}$ asymmetrically c-commands $\mathrm{Y}_{\mathrm{j}}$, then the non-terminal-to-terminal relation $\mathrm{d}$ that holds of $\mathrm{A}$, i.e. $\mathrm{d}(\mathrm{A})$, is a linear ordering of T. See Kayne, 1994: 3-6)

${ }^{3}$ In principle, H may also follow XP, but then the notion "precedence" would not conform to common usage; it would nevertheless suffice to establish a definable linear relation between $\mathrm{H}$ and XP.

${ }^{4} \mathrm{~A}$ weaker claim would be that there must be some linear ordering, but that at the same time this ordering is not necessarily the same from one construction to the other. But then the theory says nothing more than AB cannot be equal to BA, which - linearity given - is tautological. This weaker interpretation is certainly not what Kayne had in mind.

${ }^{5}$ The present article can in no way be considered comprehensive as far as verbs of speaking in the role of quotatives are concerned. I refer the reader to some intriguing observations in von Roncador (1988:112 ff) and to the rich literature quoted therein.

${ }^{6}$ My little information about FC in Assamese rests on Subbarao, Rao, Saxena and Rau (1989) who provide the following example where the finite verb seems to be moved to the right of buli:

$$
\begin{aligned}
& \text { m?i tomar gh?rloi buli ahib? khoisili } \\
& \text { I your place BULI come want-PTS } \\
& \text { "I wanted to come to your place" }
\end{aligned}
$$

${ }^{7}$ The data on Dakkhini-Hindi stem from Arora (1985) to which I did not have access. Here I quote from Davison (1993). The - $k i$ that appears in Dakkhini-Hindi seems to be a different item than the initial $k i$-complementizer. Final $-k i$ is affixal, while initial $k i$ is not. Furthermore, initial $k i$ is not confined to embedded interrogatives at all. Subbarao and Arora (1989) mention $-k i$ as an affixal FC; in their examples, $-k i$ is always dubitative/interrogative e.g.,

$$
\begin{aligned}
& \text { uno kyaa bolaa ki mere } \quad \text {-ku bataanaa } \\
& \text { he what said KI I }
\end{aligned}
$$

The authors conclude that $-k i$ in Dakkhini is a syntactic borrowing from Telugu where we find (besides -ani) the FC -oo which largely seems to be the syntactic model for final $-k i$.

${ }^{8}$ The first description of functions of bole seems to be Singh (1980); Singh took bole and je both as complementizers. I will show that there is little reason to reject his conclusion in favor of a more reductionist account. 
${ }^{9}$ All we have to assume then is that Assamese lacks the Doubly-Filled-COMP Filter (DFCF) while Bengali and Oriya, where such constructions are impossible, do not. One reviewer suspects that this might be a case of "floating" je, as found in Bengali (cf. Dasgupta, 1983, who calls this clause-internal je an "anchor"). Floating je has profoundly different properties than clause initial je. One prominent difference is that it may never occur in a CP to the right of the verb. If Assamese permits floating je, it would be surprising to find it in a context as in (5). Since floating je is not confined to second position, we would in that case also expect cases such as

(i) $\quad \ldots$ [kaki bill-e je juwal kali $\mathrm{t}_{\mathrm{i}}$ dekhisil $]$

(ii) $\quad$... [bill-e je juwal kali kak dekhisil]

${ }^{10}$ I cannot discuss relative clauses here, but it is suggestive that these languages have two positional types of relatives: Right-adjoined relatives which behave more or less like those in English and elsewhere, and leftadjoined relatives, the so-called "correlatives" which have markedly different properties (cf. Dasgupta (1980) for Bengali and Srivastav (1991) for Hindi. Consider the following Hindi examples from Srivastav's work:

correlative; left adjoined

right adjoined REL girl standing is DEM tall is "The girl who is standing is tall" vo laRkii jo kharii hai lambii hai DEM girl REL standing is tall is

${ }^{11}$ Cf. Dutch, English and German dat, that, daß versus of, if, ob, the latter of which can only be used for interrogatives. Another example would be Modern Greek which displays oti, pu, na; see Roussou (1994) for discussion.

${ }^{12}$ This seems to be the case, at least, for Turkish where we can also observe hybridity: The indigenous complementizer is the final affix dig, while extraposed finite clauses are headed by the initial element $k i$ that has been borrowed from Persian. The South-Asian linguistic area does not easily lend itself to firm conclusions about mutual influence. The syntax of the Indo-Aryan languages seems to be heavily influenced by Dravidian substrata (cf. Klaiman (1977) with respect to Bengali), but could as well be influenced by Middle-Eastern superstrata. In my view, verbal elements that play a dominant role in quotatives around the globe can naturally be subsumed under the covering category "complementizer". Given the fact that the complementizers of the better understood languages are historically a rather heterogeneous set too, I fail to see why UG should not allow a de-semanticized verb of speaking to be grammaticalized as a subordinator. A theory which acknowledges the function of verbal subordinators while labelling them differently would certainly not be more parsimonious. This does not preclude the possibility that quotatives serve rather different purposes than other complementizers.

${ }^{13}$ While Singh working in a framework of the seventies proposed the coexistence of two phrase structure rules, S' COMP S and S' S COMP, in the grammar of Hindi, Alice Davison (p.c.) suggests that Hindi may license embedded clauses to the left of the verb by Case, and that the element ke liye which follows infinitival complements may in fact be a postpositional Case that is selected by the matrix verb; cf. Subbarao (1984). See also note 46.

${ }^{14}$ There is yet the option of generating $k i$ as a FC as proposed by Sabel (1997). The motivation to consider this possibility is that Hindi and some typologically related languages allow for scrambling from $k i$-clauses. In order to derive the non-barrier status of $k i$-clauses, Sabel assumes that $k i$ is actually a FC which incorporates into the matrix verb, and that this is followed by extraposition of the remnant $\mathrm{CP}$ :

(i) $\quad\left[\mathrm{CP} 1 \quad \ldots\left[\begin{array}{lllll}\mathrm{CP} 2 & \ldots & \mathrm{V}_{2} & \mathrm{ki}\end{array}\right] \mathrm{V}_{1}\right]$

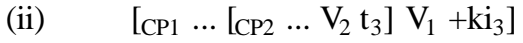

(iii) $\quad\left[\begin{array}{lllll}\mathrm{CP} 1 & \ldots . & \mathrm{t}_{4} & \mathrm{~V}_{1}+\mathrm{ki}_{3}\end{array}\right]\left[\begin{array}{llll}\mathrm{CP} 2 & \ldots & \mathrm{V}_{2} & \mathrm{t}_{3}\end{array}\right]_{4}$ $k i$-incorporation

extraposition 
${ }^{15}$ Consider Southern and other more liberal varieties of German where clear $d a \beta$-t effects could hardly been attested:

(i) Wen $n_{i}$ glaubst du, daß der Hans $t_{i}$ eingeladen hat?

who believe you that the Hans invited has

"Who do you believe that Hans has invited?"

(ii) Wer $\mathrm{r}_{\mathrm{i}}$ glaubst du, daß $\mathrm{t}_{\mathrm{i}}$ den Hans eingeladen hat?

who believe you that the Hans invited has

"Who do you believe has invited Hans?"

The problem with these representations is that they suggest a unique position from which extraction proceeds, but German being a scrambling language, the trace of the subject in (ii) may actually be in a VP-internal focus position to the immediate left of the verb, while the object NP has been scrambled out of VP. Many current analyses of German converge on this basic picture. Notice that in the was-für construction where was is extracted from a constituent that remains in situ (the für-phrase) we can see that extraction from the VP-external subject position is rather bad, while the example improves considerably once we place the remnant für-phrase to the immediate left of the verb:

(iii) ??Was ${ }_{i}$ glaubst du, daß $\left[\mathrm{t}_{\mathrm{i}}\right.$ für Leute] den Hans besucht haben?

what believe you that for people the Hans visited have

"What kind of people do you think have visited Hans?"

(iv) Was ${ }_{i}$ glaubst du, daß den Hans $\left[\mathrm{t}_{\mathrm{i}}\right.$ für Leute] besucht haben?

For discussion of similar effects in connection with that-trace in English, see Culicover's (1992) so-called "adverb effect" and the account of it in terms of CP-recursion in Browning (1996).

${ }^{16} \mathrm{~A}$ case in point would be the expletive construction with there.

(i) $\quad\{$ There $/ *$ it $\}$ is a man in the garden

The indefinite will be illicit in this construction unless it can be associated (by covert movement) with the subject position occupied by the expletive there. The assumption is that unlike it, the expletive there cannot check nominative Case, while it does contain a nominal feature that is able to check a strong Dfeature associated with the functional head $\mathrm{T}$ (ense). Raising of the indefinite, in earlier versions connected with expletive replacement, would satisfy its Case licensing requirement.

${ }^{17}$ More precisely, the category that is able to check F must be the closest category a in agreement with the Minimal Link Condition (Cf. Chomsky, 1995: 311). In chapter 4 of Chomsky (1995), the Greed principle is ultimately given up in favor of Attraction; I mention it here nevertheless because it delineates an eventual correlation between movement and IP-variability in a transparent way.

${ }^{18}$ I confine myself to German.

${ }^{19}$ Cf. van Riemsdijk's (1978) analysis of PPs according to which the so-called "R-pronouns" da/wo are moved to SpecPP: $\left[\mathrm{PP}\left\{d a /\right.\right.$ wo $_{i}\left[\mathrm{P}^{\prime}\right.$ mit $\left.\left.\mathrm{t}_{\mathrm{i}}\right]\right]$. In Bayer (1996), I proposed that the R-elements actually undergoing local movement are either overt or silent clitics. The difference is not relevant in the present context.

${ }^{20}$ Such an analysis is supported by the fact that non-finite clauses strongly tend to be included in the matrix verbal complex. The following examples from Bengali (drawn from Bayer, 1996:254) are both possible, but (ii) exists only as a marked option:

(i) tumi rOnjon-ke [baRi je -te] bole-cho you Ronjon-OBJ home go-INF tell-PTS2

"You told Ronjon to go home"

(ii) tumi rOnjon-ke bole-cho [baRi je-te] 
${ }^{21}$ This is by no means an isolated fact; cf. Bayer (1995) for relevant data and comparison with infinitival constructions in German.

${ }^{22} \mathrm{We}$ will in section 3.4 return to the question whether IP could be expected to move at all.

${ }^{23}$ Cf. Dasgupta (1983) who discusses "floating" je. Notice that a structure like (12a) cannot even be derived under the option that je floats. Floating je must always remain to the left of $\mathrm{V}$. It can never appear at the right periphery of IP. See also note 9 .

${ }^{24}$ See Singh (1977) for Hindi.

${ }^{25}$ The only example with two occurrences of the same lexical complementizer I became aware of is the following example from Lhasa Tibetan that is presented in Saxena (1995:354), although one should notice that one element is a full form while the other is a clitic:

(i) r?psuû -qi sè -na ? a ya šá tsáwa ne? ma -q?? -s $\quad 1$ ?p-p? -ree goat-tail-ERG SAY-COMP I TOP meat at all NEG-want-QUOTE say-PERF/INFERENCE

"The goat-tail said, 'I don't want any meat'"

${ }^{26}$ This can be seen in example (i):

(i) e kotha bol-e ram ghumi-ye por-1 -o thus speech say-PPT Ram sleep -LOC fall-PTS-3

"Having said that, Ram fell asleep"

${ }^{27}$ Dasgupta calls floating particles such as je and a handful of elements with similar syntactic behavior anchors. He distinguishes these from COMP-like elements which he calls subjoiners. See also note 9.

${ }^{28}$ The examples in (14) could be mistaken as cases of "X-second", but as pointed out in Bayer (1996), this analysis in not tenable: je can "float" through the clause. See also note 8 and the discussion in Dasgupta (1983).

${ }^{29}$ According to the data in Singh (1977) and McGregor (1972: 121), ke liye is confined to non-finite clauses while $k i$ is confined to finite clauses. Thus, the only plausible motivation for movement would in this case be the one we have already mentioned, not the clitic nature of ke liye.

${ }^{30}$ I recall one German example by Beatrice Santorini which she - at that time - considered grammatical, while I did not:

(i) [Meinen Mann mit einer anderen tanzen $]_{i}$ würde ich nie $t_{i}$ lassen my husband with an other(woman) dance would I never let

"I would never allow my husband to dance with another woman"

I cannot exclude such a possibility in general, however. According to Santorini (1992), small clause

${ }^{31}$ Koopman's theory retains a more traditional approach to the X-bar theoretic spec-head-complement articulation than Kayne's theory. While Kayne replaces X' by XP in order to prevent it from c-commanding the specifier, Koopman retains $\mathrm{X}^{\prime}$. In her theory, a linear ordering of terminals in the sense of the LCA is only achieved, if spec and head are not filled simultaneously, i.e. each filled specifier must be associated with an empty head, and a filled head must be associated with an empty specifier. The details of this are not central for my further argumentation.

${ }^{32}$ Notice that without reconstruction (or its implementation by the copy-and-delete process) one cannot rule out (i).

(i) $*[\text { Who came }]_{\mathrm{i}}$ John thought $\mathrm{t}_{\mathrm{i}}$ ?

The reason for the grammaticality of $(18 \mathrm{~b} / 19)$ cannot be that, due to spec-head agreement with the raised $d o$, reconstruction would be suspended. If this were the case, anaphoric binding as in (ii) could not be explained: 
${ }^{33}$ Some of Ross' examples show that Slifting may affect complements which are obligatorily introduced with a complementizer, e.g. I \{hazarded/conjectured/foresaw/ascertained\} \{that $/ *\}$ he would be able to clap his little hands. To derive He would be able to clap his little hands, Sheila \{hazarded/conjectured/fore-saw/ascertained\} C-deletion becomes obligatory.

${ }^{34}$ This had already been noticed in Jackendoff (1972) and Ross (1973), although with different conclusions. On the basis of German data, Reis (1995) argues convincingly that cases that where treated as extractions from CPs with V-initial order (Wen glaubst du hat Peter angerufen? "Who do you believe Peter has called?") are more successfully analyzed as matrix questions with an inserted parenthetical.

${ }^{35}$ The contrasts observed in German are crystal clear. I would like to mention, however, that there have been reported examples from English which indicate that this is not always the case. Consider the following contrasts taken from Fiengo, Huang, Lasnik and Reinhart (1988).

(i) a. $\quad * \mathrm{Who}_{\mathrm{i}}$ do you think that [[pictures of $\left.\mathrm{t}_{\mathrm{i}}\right]$ are on sale]?

b. $\quad$ Who $\mathrm{W}_{\mathrm{i}}$ do you wonder [[which pictures of $\left.\mathrm{t}_{\mathrm{i}}\right]_{\mathrm{j}}\left[\mathrm{t}_{\mathrm{j}}\right.$ are on sale $\left.]\right]$ ?

(ii) a. *Vowel harmony $y_{\mathrm{i}}, \mathrm{I}$ think that $\left[\left[\operatorname{articles}\right.\right.$ about $\left.\mathrm{t}_{\mathrm{i}}\right]$ have been published]

b. $\quad$ ?owel harmony $\mathrm{i}_{\mathrm{i}}, \mathrm{I}$ think that $\left[\left[\text { articles about } \mathrm{t}_{\mathrm{i}}\right]_{\mathrm{j}}\right.$, [you should read $\left.\left.\mathrm{t}_{\mathrm{j}}\right]\right]$

\section{${ }^{36} \mathrm{Cf}$. Fiengo et al. (1988:91) for similar examples.}

${ }^{37}$ German shows a notable exception with respect to scrambled infinitival clauses. Scrambled infinitives, but not topicalized ones, do not induce the freezing effect. Thanks to Joachim Sabel for reminding me of this fact. See for discussion Grewendorf and Sabel (1994).

${ }^{38}$ The notion of a "frozen" structure or "freezing" goes back to J. R. Ross; cf. Culicover (1976: 297ff) among others. I use "freezing" here as a non-technical notion. Originally, it relates to technical details that have ceased to play a role in linguistic theory, namely that a transformation cannot affect a node that has been created by a non-structure-preserving transformation. For a broad discussion within recent syntactic theory, see Müller (1997: ch.4).

${ }^{39}$ Thanks to Tanmoy Bhattacharya, Probal Dasgupta and M.T. Hany Babu for supplying me with the examples and for discussion of their status in discourse.

${ }^{40}$ One reviewer suggests that the problem for (8) could be overcome, if we resort to covert feature movement (Move-F) or to a process of unselective binding as suggested in Chomsky (1995). As I have pointed out in Bayer (1996: 272ff), however, the assumption of a silent scope indicator which attracts or binds occurrences of +wh words in these languages would allow far too many possibilities of wide scope. As has been observed repeatedly, wh-in-situ OV-languages with "extraposed" $k i$ - or je-clauses never show wide scope of + wh operators from such complements. This is not predicted, if the matrix clause may host a silent attractor of or binder for the wh-in-situ element. My conclusion in Bayer (1996) was that wh-scope in these languages must be fixed by self-driven, i.e. ultimately semantically conditioned covert movement, and that this movement is constrained by directionality: FC-clauses are to the left of $\mathrm{V}$ and thus canonically governed; IC-clauses $(k i-/ j e-$ clauses) are to the right of $\mathrm{V}$ and thus non-canonically governed if governed at all. See section 5 for more discussion.

${ }^{41}$ See also Chomsky (1995:334ff). Choms ky takes "the LCA to be a principle of the phonological component [...]". p.340.

${ }^{42}$ This has been pointed out and elaborated on in Bayer (1996); see also more typologically oriented work such as Kuno (1973), Grosu and Thomp son (1977), Dryer (1980) and Hawkins (1990) for relevant generalizations. The original observation concerning Bengali is due to Singh (1980). What we know so far will have to be reexamined as more South Asian languages enter the picture. A taste of the expected complications is given by the data on complementizers from lesser known Indo-Aryan and Dravidian languages in Patnaik (1997). Thanks to Alice Davison for making Patnaik's handout accessible to me. 


\footnotetext{
${ }^{43}$ This amounts to an explanation based on directionality as developed in Bayer (1996).

${ }^{44}$ Thanks to Jaklin Kornfilt for the examples and for a tutorial on complementation in Turkish.
}

${ }^{45}$ For reasons of space, I cannot go into the theory itself. It should suffice here to see that in a VO-language extraction of or from a CP-complement is regular, while extraction of or from an "extraposed" CP-complement in an OV-language would violate a directionality constraint. Based on important insights in Kayne (1984) and Koster (1987), I tried to capture this in Bayer (1996) by devising a theory according to which in OV-languages $\mathrm{VP}$ is a barrier for complements to the right of $\mathrm{V}$ unless there is an overtly manifested feature (+wh, +neg etc.) that induces chain formation with material on the non-canonical side of $\mathrm{V}$. The interested reader is referred to chapters 6 and 7 of Bayer (1996) where among other things overt Wh-movement in such languages is discussed.

\begin{abstract}
${ }^{46}$ In the description of Hindi, Case particles such as $k o$, the marker of direct or indirect human or animate objects are often identified as 'postpositions'; cf. McGregor (1972). According to Chatterjee (1926, 766ff) "[u]se of post-positions to denote case relations is found in Indo] A[ryan], Kol and Dravidian." Chatterjee ascribes the use of postpositions as Case particles in Bengali to a pervasive influence from Dravidian. Let me notice, however, that the list of postpositions provided by Chatterjee does not include bole. Thus, the claim that bole could be a Case particle derives exclusively from Klaiman (1977: 304) who wants to see bole on this list.
\end{abstract}

${ }^{47}$ The problem of German word order cannot be reduced to raising or not raising to a left VP-peripheral functional position for Case-checking. With the possible exception of extra heavy NPs, the order is in-variably $[\mathrm{N}(\mathrm{P}) \mathrm{V}]$, never [V N(P)]. It is a simple but significant observation that children at the earlier stages of syntactic development and seriously agrammatic aphasics say kuchen essen (cake eat), milch trinken (milk drink) etc. instead of *essen kuchen, *trinken milch etc. Arguably, the bare nouns involved do not have Case at all. Thus, the V-final order must have an ontological status here that is independent from raising to a Case position. Pre- as well as postpositional usage is observed with certain P-heads such as wegen (because of) or gemäß (according to). Corver and van Riemsdijk (1997) argue that in German, the prepositional order P NP is basic and that the postpositional order is derived by movement of $\mathrm{P}$ to a functional P-slot to the right. See also Gibson and Wexler (1994:422) on the issue of a non-uniform head-complement parameter. It should be noticed though that the status of Dutch and German is under debate. Zwart (1997) argues for a VO-analysis of Dutch according to which nominal objects and predicates raise to the left of V, while CPs and certain other elements fail to undergo raising. The issue is far from settled. In Bayer (1996) I have presented a number of arguments against a VObasis for German and the Indic languages. With the exception of Kayne (forthcoming), these arguments have not been addressed by proponents of universal head-initiality so far.

${ }^{48}$ See also Pintzuk (1991) for Old English and Rögnvaldsson (1996) for Old Icelandic.

${ }^{49}$ Santorini (1992:619).

${ }^{50}$ Lust, Bhatia, Gair, Sharma and Khare (1995) investigate the acquisition of anaphora in Hindi. It has previously been found that the early acquisition of anaphora in English is guided by "forward directionality" in the sense that a proform should follow and not precede its antecedent. As the authors note, Hindi, is a directionally "mixed" language by the fact that it is predominantly left-branching but has finite complements and one type of relative clauses on a right branch; in addition, Hindi shows mixed order for adverbial subordinate clauses. Interestingly, the experimental investigation of children's processing of left - versus right-branching jab ("when") clauses in Hindi reveals that the preference for forward directionality is confined to right-branching structures, while the preference reverts to backward directionality in the processing of left-branching structures.

${ }^{51}$ Although the areal constraints on linguistic variation are quite remarkable in South-Asian, Sprachbund phenomena of this kind are not unique at all. Prominent examples are found on the Balkans where languages from branches of Indogermanic as diverse as Slavic, Romance and Greek converge surprisingly in the decay of the infinitive, in the syntax of operators and in their clitic systems.

${ }^{52}$ Cf. Paul (1975:402).

${ }^{53}$ I call these j-relatives because all relative pronouns begin with /j/: je ("who", "which"), ja-ke ("whoACC/DAT"), ja-r ("whose" (="who-GEN")), jo-khon ("when") etc. The fact that unlike the correlative relative clauses $j$-relatives follow their nominal heads, ties in naturally with the observation that je-complements regularly appear with a nominal pleonastic element that may also be dropped. In Hindi, these elements are the demonstrative yeh ("this") or the dummy -DP yeh baat ("this matter"). In Bengali, we find ta ("it") $e$-Ta ("this - 
CF") and e kOtha ("this talk/story/sentence"). Consider the following example:

(i) chele-Ta ([e kOtha]) jan -e na [je baba aS -be ]

boy-CF this talk know-3 not JEfather come-FUT3

"That his father will come, the boy does not know this" 